\title{
Removal of Metallic Anions from Dilute Aqueous Solutions by Polymer-Surfactant Aggregates
}

L.C. Shen ${ }^{\text {a }}$ J. Wu ${ }^{\text {b }}$, S. Singh ${ }^{\text {a }}$, N.P. Hankins ${ }^{\text {a* }}$

${ }^{a}$ Laboratory of Sustainable Water Engineering, Department of Engineering Science, Parks Road, The University of Oxford, OX1 3PJ, United Kingdom

5 bepartment of Chemical \& Biomolecular Engineering, National University of Singapore, Singapore 117585

\section{Abstract}

A new application of polymer-surfactant aggregates has been developed to remove dilute metallic anions, such as $\mathrm{CrO}_{4}{ }^{2-}$ and $\mathrm{Fe}(\mathrm{CN})_{6}{ }^{3-}$, from aqueous solutions. This process uses anionic polymers, such as poly (sodium 4-styrenesulfonate) (PSS) or poly (acrylic acid) (PAA), as a back-bone structure onto which cationic surfactants, such as myristyl trimethyl ammonium bromide (MTAB), form micelle-like aggregates. The resulting structures, called polymer-surfactant aggregates (PSAs), have the ability to remove anions from solutions, and to form larger flocculated aggregates through a process of intermolecular association. The flocculated aggregates can then be separated out from the solution through a settling or coarse filtration step. In the work presented here, the results show that $99 \%$ of 0.1 $\mathrm{mM} \mathrm{Fe}(\mathrm{CN})_{6}{ }^{3-}$ and $80 \%$ of $0.2 \mathrm{mM} \mathrm{CrO}_{4}{ }^{2-}$ can be removed at optimum dosages. The change in conductivity with the change in surfactant concentration is plotted to reveal changes in the state of the system, and to detect the point of formation of the PSAs. The results indicate that the PSAs, which form at surfactant concentrations well below the critical micellar concentration, are responsible for removing the metallic anions. This process is effective for metallic anion removal over a $\mathrm{pH}$ range from 4.5 to 6 and a temperature range from 5 to $50{ }^{\circ} \mathrm{C}$. Furthermore, both salt and organic contaminants did not significantly interfere with the anion removal efficiency. Such a PSA process thus has potential applications for the efficient removal of dilute anions, and metallic anions in particular, during process effluent water treatment.

Keywords: Polymer-surfactant aggregates; Aqueous effluent treatment; Dilute anion; Coarse filtration 


\section{Introduction}

Metallic anions are widely used in the plating and pigment industries. Like metal cations (e.g. chromium and iron), metallic anions can also be present in a stable and multivalent form in aqueous solutions. Examples of metallic anions include oxyanions and metals bound with cyanide ions, such as $\mathrm{CrO}_{4}{ }^{2-}, \mathrm{Cr}_{2} \mathrm{O}_{7}{ }^{2-}$ and $\mathrm{Fe}(\mathrm{CN})_{6}^{3-}$. They are usually found at dilute concentrations within a wide range of solutions, and can accumulate in ecological systems causing health disorders. Their presence in aqueous effluents has thus attracted a great deal of attention with respect to the development of mitigation techniques.

All metallic anion removal techniques have inherent advantages and limitations in their various applications, depending upon the characteristics of the wastewater and the treatment requirements. Ion exchange is highly effective in the removal of small amounts of contaminants at high concentrations [1-3], but the cost and secondary pollution when regenerating the resin are critical limiting factors. Thus, it is not economically feasible to treat large amounts of dilute metallic anion wastewater. Electrochemical techniques are regarded as rapid and well-controlled methods to remove both metal cations and anions. They are also associated with fewer chemical additions and less sludge production [4]. The drawbacks are high capital and running costs. Adsorption is an alternative method to treat dilute systems, but achieving a balance between the cost and effectiveness of the physico-chemical adsorbent remain a challenge [5-7]. Biosorption has proven to be a promising and sustainable removal method. It is advantageous in that it is able to treat a large capacity of wastewater and that it produces a concentrated sludge. However, the capital and maintenance costs are high $[8,9]$. Finally, the application of membrane filtration technology is an effective treatment method, but high capital and operating costs, membrane fouling and low permeate flux are limitations [10-15]. Therefore, treating dilute anion contaminated aqueous streams remains as a challenge with no clear and effective solution.

In response to the unsolved challenge and to fill the resulting niche, polymer-surfactant aggregates have already been applied for the efficient removal and recovery of cations from dilute aqueous streams $[16,17]$. This process uses a structure called a polymer surfactant aggregate (PSA), which is formed under a specific range of dosage ratios between oppositely charged polymer and surfactant ions [18, 
19]. The application of polymer and surfactant in combination resulted in the removal of heavy metal ions from dilute aqueous solutions, and surface tension measurements have been used to show that the PSA is indeed responsible for removing the metal ions [16]. Measuring the electrical conductivity of a solution containing polymer and surfactant is one of the common methods used for investigating the interactions between them in the bulk solution [20, 21]. For example, the critical micellar concentration (CMC) of a surfactant can be measured by the break point in the increase of conductivity of the surfactant aqueous solution with concentration [22]. The PSAs form at low surfactant and polymer concentrations ( $<250 \mathrm{ppm}$ cationic surfactant; $<100 \mathrm{ppm}$ anionic polymer) as a result of electrostatic and hydrophobic interactions, and contain both positive and negative charges [23-26]. In the removal process, individual nano-scale PSAs with a high surface-volume ratio bind to dilute anions via electrostatic and chelation forces. While binding with the anions, and due to having both positive and negative charges, they also associate inter-molecularly with each other. This causes charge neutralisation and leads to the formation of large flocs which precipitate out and settle under gravity. After allowing the solution to settle or after coarse filtering, the PSA-anion precipitates can be recovered; with further treatment, the PSA precipitates may be recycled, and the anions are recovered in a concentrated form. The polymer surfactant aggregate technique has the benefit of using a small amount of recyclable substrates to remove anions from dilute aqueous streams and does so without the need for expensive processing.

In this paper, the change of conductivity versus the change in surfactant concentration has been studied as a means of investigating the correlation between PSA formation and anion removal. The effects of charge density of the polymer on the treatment performance, and the kinetics of the process as a function of polymer, surfactant and anion are also studied. Finally, the effects of the separation method, $\mathrm{pH}$, temperature, and the presence of salt and organic contaminants on the anion removal efficiency are investigated.

\section{Materials and methods}

\subsection{Materials}


Poly(acrylic acid) (PAA: $\left.\left(\mathrm{C}_{2} \mathrm{H}_{3} \mathrm{COOH}\right)_{\mathrm{n}}\right)$ solutions were prepared by diluting stock PAA solutions (Sigma Aldrich, average MW <100,000, 35 wt.\% in $\mathrm{H}_{2} \mathrm{O}$ ). Poly (sodium 4-styrenesulfonate) (PSS: $\left.\left(\mathrm{C}_{2} \mathrm{H}_{3} \mathrm{C}_{6} \mathrm{H}_{4} \mathrm{SO}_{3} \mathrm{Na}\right)_{\mathrm{n}}\right)$ (average MW 1,000,000), sodium dodecyl sulphate (SDS: $\mathrm{CH}_{3}\left(\mathrm{CH}_{2}\right)_{11} \mathrm{OSO}_{3} \mathrm{Na}$ ) (purity $\geq 99.9 \%$ ) and myristyl trimethyl ammonium bromide (MTAB: $\mathrm{CH}_{3}\left(\mathrm{CH}_{2}\right)_{13} \mathrm{~N}\left(\mathrm{CH}_{3}\right)_{3} \mathrm{Br}$ ) (purity $\geq 99 \%$ ) were obtained from Sigma Aldrich, and used directly without further purification. Potassium chromate $\left(\mathrm{K}_{2} \mathrm{CrO}_{4}\right)$, potassium ferricyanide $\left(\mathrm{K}_{3} \mathrm{Fe}(\mathrm{CN})_{6}\right)$, and potassium chloride $(\mathrm{KCl})$ were purchased from Fisher Scientific (all purity $\geq 99 \%$ ).

\subsection{Methods}

Polymer, surfactant and metallic anion solutions were prepared respectively from 4000 ppm polymer, 0.1 M surfactant and 0.01 M metallic anion stock solutions made in volumetric flasks. A calculated amount of anion solution was added first and then diluted with deionised water, to mimic industrial effluent. Inorganic and organic contaminants were then added to the solution where appropriate. Next, the polymer solution was added to the mixture, followed by the surfactant solution. The mixture was then diluted with deionised water to achieve the final intended concentrations. The reason for adding polymer before surfactant is to minimise the electrostatic interactions between the surfactant and the anions in the absence of polymer. The solution was stirred by a magnetic stir bar at $200 \mathrm{rpm}$ overnight to achieve equilibrium, which was indicated by a transparent solution with precipitates visible in the bottom and on the wall of the flask. After the equilibrium was achieved, these solutions were then coarse-filtered. For the pH study and PAA-MTAB studies, the $\mathrm{pH}$ of each solution was adjusted by adding small amounts of concentrated $\mathrm{H}_{2} \mathrm{SO}_{4}$ or $\mathrm{NaOH}$ solution. The $\mathrm{pH}$ was measured by a Jenway $\mathrm{pH}$ meter. For the temperature adjustment, a hotplate stirrer with temperature control (UC152, Stuart) was used to maintain the desired temperature of the solution.

All solutions were filtered by a Millipore model 8050 dead-end filtration cell with a stirrer. The feed passed through the $20 \mu \mathrm{m}$ coarse filter under gravity, such that entities larger than the filter pore size were retained in the cell, while water and dispersed solute molecules smaller than the pore size passed 
through and into the collection vessel. The purpose of this step was to separate polymer-surfactant 110 precipitates with bound anions from the free anions, surfactant monomers and free polymers in solution. The total carbon content of solutions was measured by a total organic carbon analyser (TOC-VCPH, Shimadzu) to indirectly measure the degree of flocculation and de-flocculation, which is possible since, in the absence of organic contaminants, the only two carbon sources in the solution are the MTAB and the PAA/PSS. A reduction in the total carbon in the filtrate indicates that the PAA/PSS and MTAB formed precipitates or colloids which were filtered out. Given the independent measurement of MTAB concentration via titration, as described in reference [11], the PAA concentration in the filtrate was Equation 1:

Equation 1:

$$
\begin{aligned}
\mathrm{C}_{\text {PAA filtrate }}(\mathrm{ppm}) & =\frac{\text { Total carbon }_{\text {filtrate }}-\mathrm{C}_{\mathrm{MTAB} \text { filtrate }} * \text { Carbon content }_{\mathrm{MTAB}}}{\text { Carbon molecular weight by percentage }_{\mathrm{PAA}}} \\
= & \frac{\text { Total carbon }_{\text {filtrate }}(\mathrm{ppm})-\mathrm{C}_{\mathrm{MTAB} \text { filtrate }}(\mathrm{mM}) * 204 \mathrm{~g} / \mathrm{mol}}{0.5}
\end{aligned}
$$

Equation 1: Calculation of PAA concentration in the filtrate.

The concentrations of chromate and ferricyanide were measured by an Agilent Technologies 200 Series AA atomic adsorption spectrometer and a UV-VIS spectrometer (UV-1800, Shimadzu).

Assuming that the volume of solution before and after treatment is consistent, the substrate usage efficiency and anion removal efficiency are defined by Equation 2 :

$$
\begin{gathered}
\text { Substrate retention/usage efficiency }=\left(1-\frac{\text { Total carbon }_{\text {filtrate }}}{\text { Total carbon } \text { add removal agent }_{\text {arl }}}\right) \times 100 \% \\
\text { Anion removal efficiency }=\left(1-\frac{\mathrm{C}_{\text {filtrate }}}{\mathrm{C}_{\text {origina effluent }}}\right) \times 100 \%
\end{gathered}
$$

Equation 2: Calculations of substrate retention/usage and anion removal efficiencies.

\subsubsection{Conductivity measurement}

The conductivity of solutions was measured by a YSI professional plus conductivity meter, with an accuracy of $\pm 0.1 \mu \mathrm{s} / \mathrm{cm}$ in the range below $500 \mu \mathrm{s} / \mathrm{cm}$ and $\pm 1 \mu \mathrm{s} / \mathrm{cm}$ in the range above. A $500 \mathrm{ml}$ 
solution of PAA/PSS and/or anion was prepared from stock solutions; for the $\mathrm{pH}$ effect studies, the $\mathrm{pH}$ was adjusted by adding small amounts of concentrated $\mathrm{H}_{2} \mathrm{SO}_{4}$ or $\mathrm{NaOH}$ solution. $1 \mathrm{ml}$ of $0.01 \mathrm{M}$ of $\mathrm{pH}$ corrected surfactant solution, containing the same concentration of polymer as the prepared bulk solution (so as maintain the polymer concentration in the bulk), was then added stepwise into the solution, and a reading was taken when the conductivity reading had stabilised. A correction factor for the dilution was considered. Due to limitations in the measurement accuracy, at a high ionic strength condition (high surfactant dosage), data was rounded-off to the nearest integer, and the trend of the change of increase of conductivity above $500 \mu \mathrm{s} / \mathrm{cm}$ was less smooth than that below $500 \mu \mathrm{s} / \mathrm{cm}$. Fortunately, the low surfactant concentration zone, which has a relatively high measurement accuracy $(0.1 \mu \mathrm{s} / \mathrm{cm})$, is the dosage range of interest.

\section{Results and Discussion}

3.1 Studies of conductivity measurements

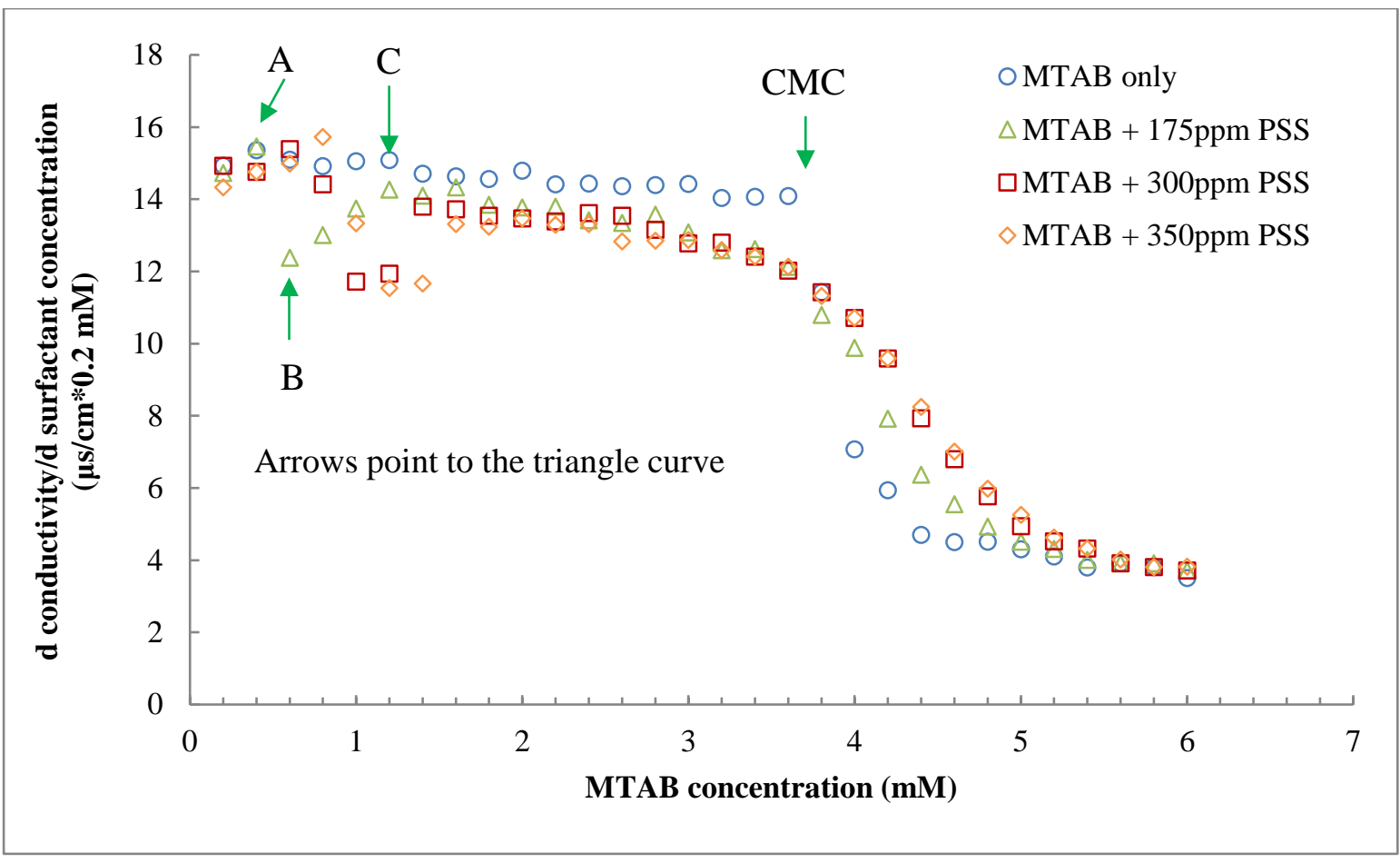

Figure 1: Differential change of conductivity versus differential change in surfactant concentration for the MTAB system with the addition of different amounts of PSS (arrows point to the triangular data 
points of MTAB + 175 ppm PSS; A represents the first falling point, B represents the bottom of the valley and $\mathrm{C}$ represents the transition point towards level off).

The electrical conductivity of the PSS-MTAB system is studied to investigate directly the polymersurfactant interactions in bulk solutions. When the conductivity increases with increasing concentration of pure MTAB, the CMC is found as the transitional point of the slope, but this transitional point can be difficult to locate. Thus, some researchers have tried various ways of plotting the conductivity versus surfactant concentration, such as the square root of surfactant concentration versus the first derivative and the surfactant concentration versus the first derivative [20,27]. In this paper, to represent these subtle changes in the conductivity, the differential change of conductivity versus the differential change in MTAB concentration is plotted against the MTAB concentration. In Figure 1, a distinct valley is observed in the plot in the presence of permanently charged polymer (PSS). It is observed that varying the amounts of PSS in the MTAB solution does not change the overall pattern of the plots, but the position of the salient points in the $\operatorname{dip}(\mathrm{A}$ : the beginning, B: the bottom, and C: the end) is shifted towards a higher MTAB concentration with increasing PSS concentration.

Before point $\mathrm{A}$ at low MTAB concentrations, there is a short region of constant increase of the conductivity derivative. At such low concentrations, the electrostatic and hydrophobic forces are not strong enough to cause interactions with PSS, so the added MTAB exists in the form of monomers only. Thus, the differential change of conductivity per differential change of surfactant concentration follows the same trend as that of the pure MTAB system. However, at concentrations above point A, the addition of MTAB forms aggregates on the PSS chains, and consequently the differential change in conductivity per differential change in surfactant concentration diminishes. The reason is that the aggregates (minimicelles) on the PSS have a smaller associated electrical mobility and charge per monomer unit than that of free monomers, which results in a lower electrical conductivity of the system. This phenomenon is very similar to the slowdown in the differential change of conductivity versus differential change in surfactant concentration which occurs after the CMC. The resulting structure is called a PSA. In addition, the transparent solution becomes turbid at point A, which indicates that colloidal structures (PSAs) are now present in the solution. Point A, therefore, can be used to estimate the critical formation 
concentration (CFC) for the PSS-MTAB system, which is the concentration at which PSAs start to form rapidly in the bulk solution.

The bottom of the dip (point B) represents the concentration at which the proportion of MTAB used to form the PSAs is at its maximum. The differential change in conductivity versus differential change in surfactant concentration returns to a constant level after point $\mathrm{C}$, which is the point at which there is a maximum number of PSAs formed on the PSS backbone in the solution. Point $\mathrm{C}$ is regarded as the optimum dosage ratio between PSS and MTAB to form PSAs for treating anionic solutions; this is because the interaction of polymer chains with surfactant aggregates is maximised and that with free monomers and micelles is minimised at this point. After this point, the plots with PSS addition follow the pattern of the pure MTAB plot once again; additional surfactant has little or no further interaction with the polymer chains.

In a sense, point $\mathrm{A}$ to $\mathrm{C}$ represents a process of polymer saturation to form PSAs. It is important to note that all these transitional points occur at higher MTAB concentrations with increasing amounts of PSS, because more MTAB is needed to saturate the PSS chains. Moreover, the changes of conductivity differential around the CMC (transitional zone) are less abrupt than for the pure MTAB system. The possible explanation for this latter observation might be that the dynamic balance between micelles and monomers is disrupted, due either to the presence of the PSAs, the hydrophobic binding of monomers with flocculated PSAs, or between the monomers and the PSS chains. 


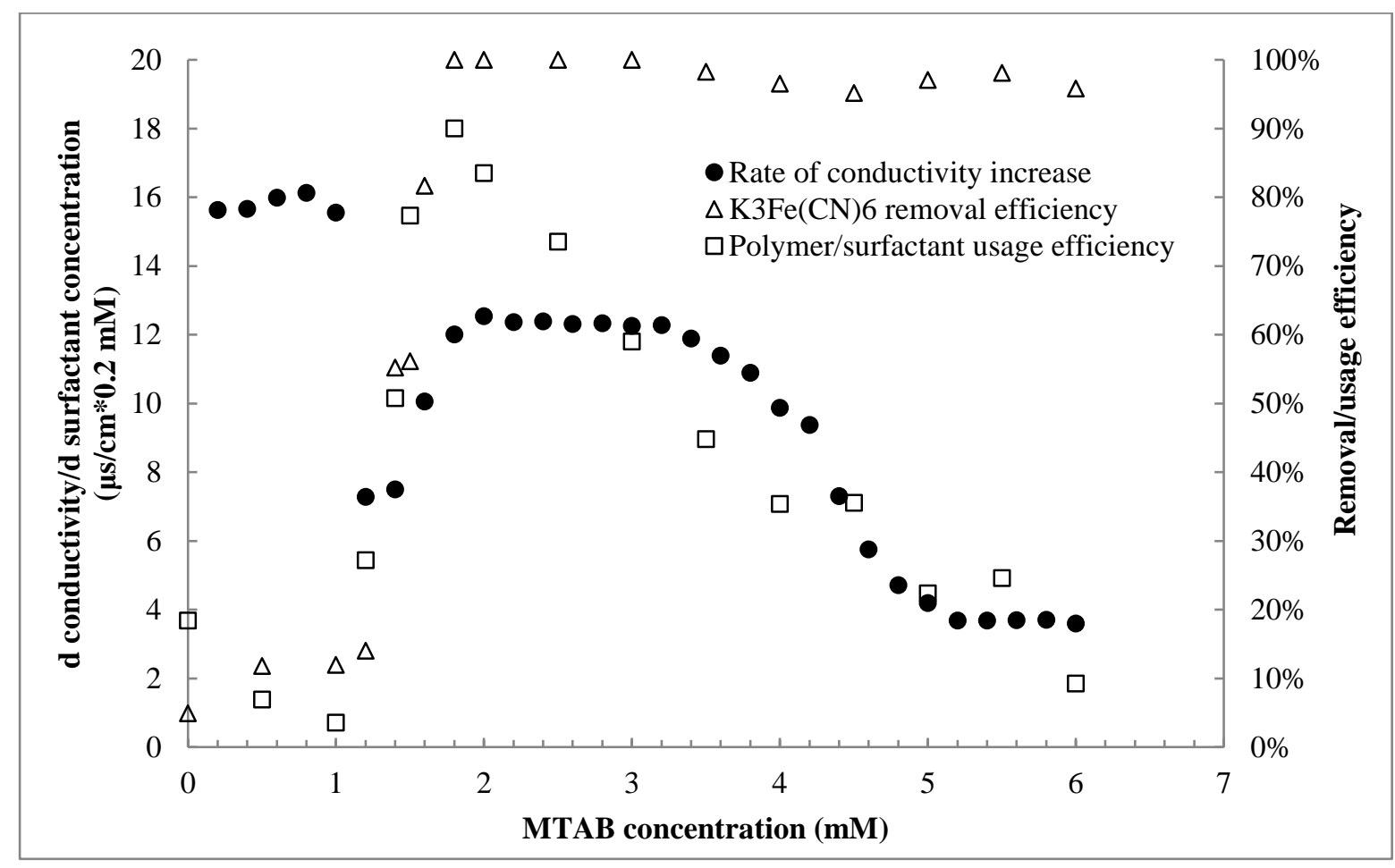

Figure 2: Differential change of conductivity versus differential change in surfactant concentration, $\mathrm{Fe}(\mathrm{CN})_{6}{ }^{3-}$ removal and substrate usage efficiencies at $300 \mathrm{ppm}$ PSS and $0.1 \mathrm{mM} \mathrm{Fe}(\mathrm{CN})_{6}{ }^{3-}$ with various MTAB concentrations.

To confirm the interpretation of the differential change of conductivity per differential change in surfactant concentration, the results are plotted against removal efficiency and substrate usage efficiency (Figure 2). The removal and substrate usage efficiencies start to increase rapidly at the first falling point in the conductivity change plot, which is the equivalent to point $\mathrm{A}$ in Figure 1. With the formation of PSAs after 1mM MTAB, the removal efficiencies increase towards the highest level, which is at the transitional point to the second plateau of conductivity change (equivalent to point $\mathrm{C}$ in

210 Figure 1). This confirms that the optimum dosage can be estimated by conductivity measurements. After the optimum dosage, the removal efficiency remains at a high level. However, the substrate usage efficiency starts to decrease, because the polymer chains are saturated and most of the additional monomeric MTAB is able to pass directly and unused through the filter to the filtrate. The substrate usage efficiency continues to decrease after the second falling point (the $\mathrm{CMC}$ ), because the pore size of the coarse filter is much bigger than the size of the micelles, so that the micelles can also pass through into the filtrate. 


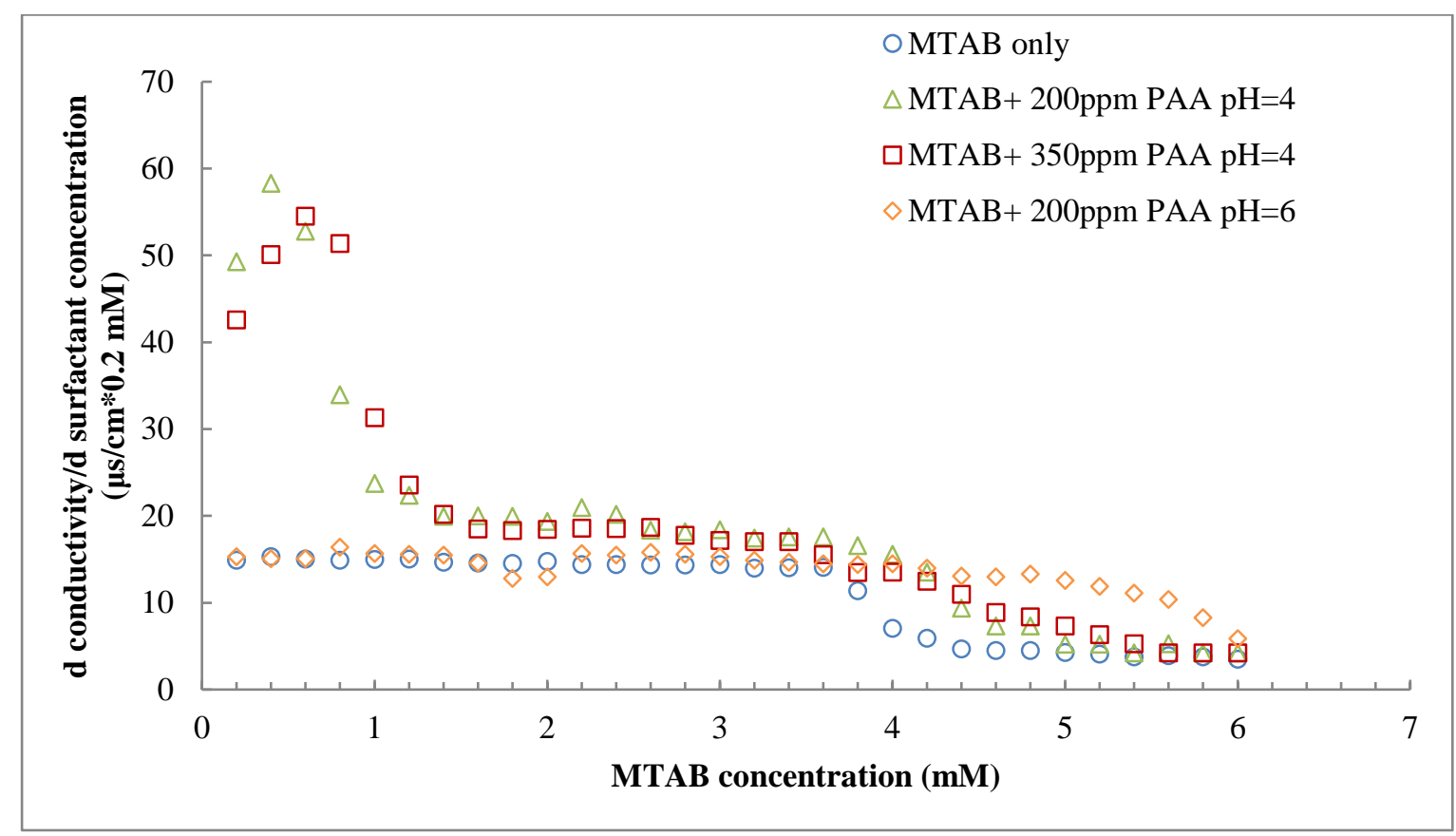

Figure 3: Differential change of conductivity versus differential change in surfactant concentration for the MTAB system, with different amounts of PAA at different $\mathrm{pH}$ values.

Apart from studying the permanently charged polymer PSS, the weakly acidic polymer PAA is also investigated. The rationale for investigating the PAA is to explore the effects of the polymer charge density on the formation of PSAs and their treatment performance. This is because PSAs containing a pH-sensitive polymer, such as PAA, and monomer MTAB may be recycled by manipulating their charge density via $\mathrm{pH}$. Figure 3 shows the effects of different amounts of PAA at different $\mathrm{pH}$ values on the interactions between PAA and MTAB.

The PAA is a weak acid, and the $\mathrm{pH}$ of the solution will gradually decrease with increasing concentration of PAA if the $\mathrm{pH}$ is not adjusted. To evaluate the effects of $\mathrm{pH}$ on the interactions, both $\mathrm{pH}$ adjusted and $\mathrm{pH}$ unadjusted samples are studied by conductivity measurements. Comparing the unadjusted $200 \mathrm{ppm}$ and 350 ppm PAA plots (at pH 4), both of them have a high differential change of conductivity versus differential change in surfactant concentration at the beginning of the addition of MTAB (Figure 3). The reason for this is that the addition of MTAB induces the disassociation of protons from the PAA. Below the MTAB concentration at the peak, the added MTAB contributes to the CFC and at the same time promotes the disassociation of PAA; the dissociated protons cause the further increase in the change of conductivity. With further addition of MTAB, the usual turbidity and 
precipitation are observed at the peak. After the peak, less and less PAA remains protonated and some of the $\mathrm{PA}^{-}$anions form precipitates which are less conductive than the free $\mathrm{PA}^{-}$, so that the differential conductivity diminishes. Eventually, all of the $\mathrm{PA}^{-}$ions are either incorporated into PSAs or precipitates.

Apart from the notable peak, no dip is measured in the $\mathrm{pH}$ unadjusted PAA-MTAB system. The possible explanation is that the appearance of a dip is due to the binding of MTAB to PAA and the formation of PSAs, and the relatively subtle associated changes in conductivity are offset by the rapid increase of the conductivity as a result of proton dissociation. To confirm this explanation, the $\mathrm{pH}$ of the solution is adjusted to 6 to dissociate the majority of PAA $(\mathrm{pKa}=4.2)$. As expected, the peak disappears after the $\mathrm{pH}$ adjustment, and the dip is regained. This may seem less obvious in Figure 3, because the scale of the $\mathrm{Y}$ axis is more than 3 times larger than that in Figure 2 or Figure 4. In short, the disassociation of PAA is induced by MTAB and the two can form PSAs; the extent of initial disassociation can be manipulated by $\mathrm{pH}$.

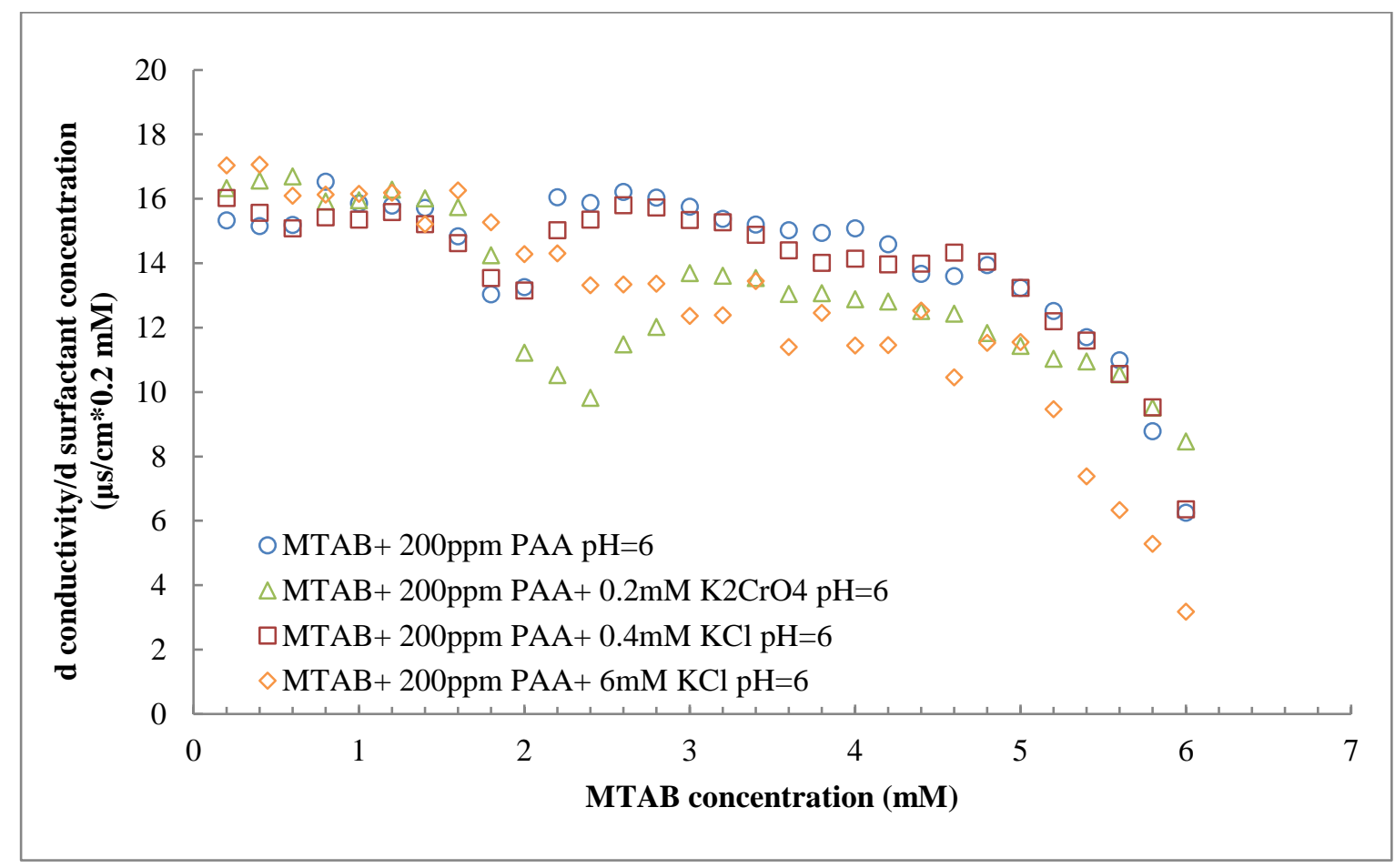

Figure 4: Differential change of conductivity versus differential change in surfactant concentration for the MTAB system at 200 ppm PAA and pH 6 with different amounts of $\mathrm{K}_{2} \mathrm{CrO}_{4}$ or $\mathrm{KCl}$.

With regard to the $\mathrm{pH}$ adjusted PAA-MTAB system, the effects of $\mathrm{CrO}_{4}{ }^{2-}$ and $\mathrm{Cl}^{-}$ions are studied in Figure 4. The purposes of testing $0.4 \mathrm{mM}$ and $6 \mathrm{mM} \mathrm{KCl}$ are to investigate the effects of the ionic 
strength on the position and depth of the dip. The results suggest that the position of the dip is independent of the ionic strength, because the start of the drop for the $0.2 \mathrm{mM}$ chromate plot is at about the same MTAB concentration (i.e. 1.2-1.4 $\mathrm{mM}$ ) for the $0.4 \mathrm{mM}$ and $6 \mathrm{mM} \mathrm{KCl}$ (Figure 4). The increasing depth of the dip is affected by the size of the charge on the ions rather than the ionic strength. In the presence of $\mathrm{Fe}(\mathrm{CN})_{6}{ }^{3-}$, a deep dip is found in Figure 2, a shallow dip is found for the $\mathrm{KCl}$ addition and a moderate dip is found for the chromate addition, these latter two in Figure 4.

In conclusion, variations in the differential change in conductivity versus differential change in surfactant concentration offers a relatively simple and reliable method to reveal detailed information about the bulk interactions between polymer, surfactant and ions, such as the CFC, the optimum dosage for anion removal, and the CMC. It also demonstrates that the removal of anions is brought about by the PSAs, and establishes the foundation for studying the dosage optimisation, robustness and removal selectivity of anions.

\subsection{Polymer and surfactant dosage and ratio}

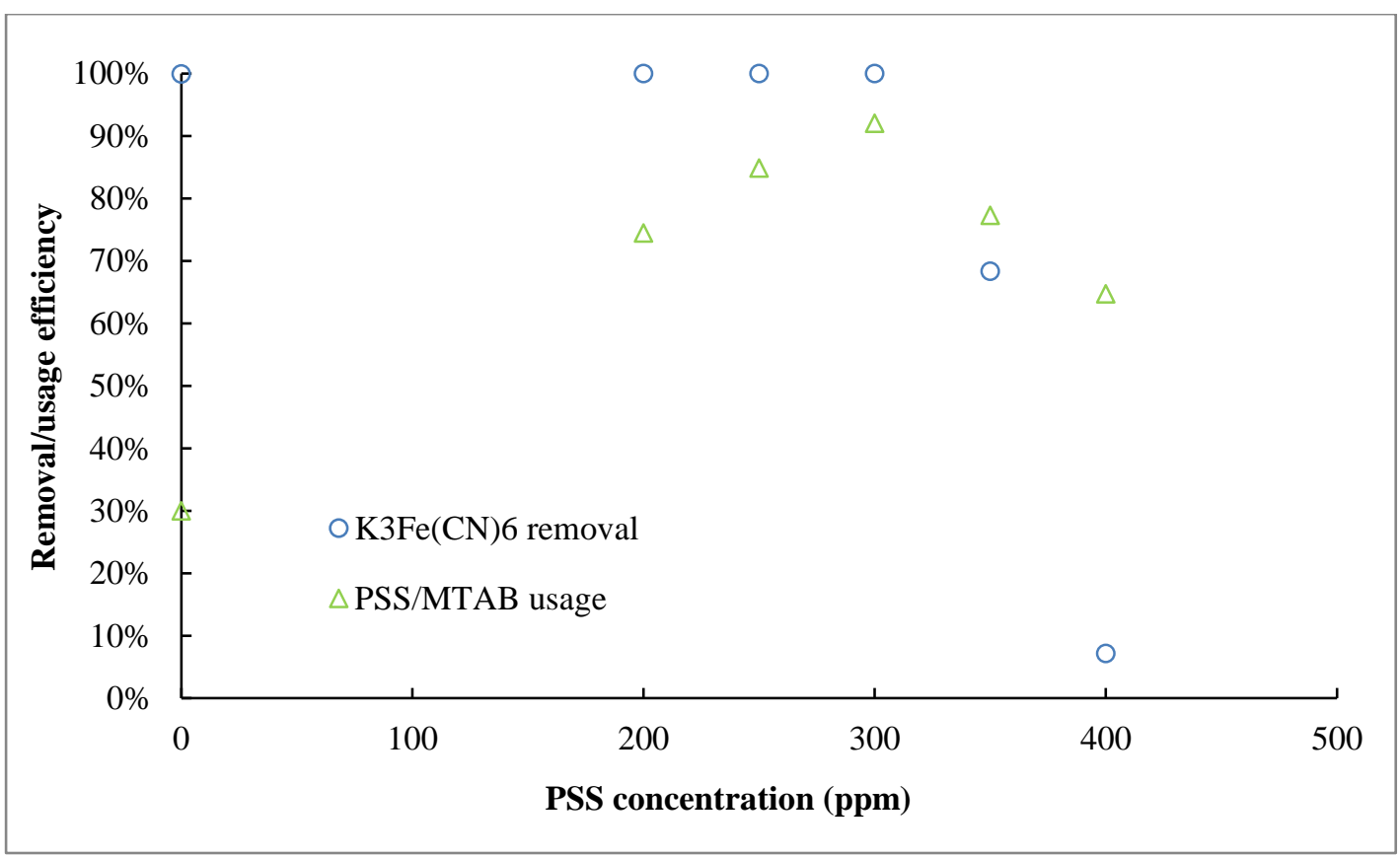

Figure 5: Dosage optimisation for 1.5 mM MTAB with different amounts of PSS to remove $0.1 \mathrm{mM}$ $\mathrm{K}_{3} \mathrm{Fe}(\mathrm{CN})_{6}$.

In the process to remove anions, PSS and PAA are mixed individually with MTAB to remove anions from dilute solutions. In Figure 5, it may seem that the addition of PSS is unnecessary, because 
$\mathrm{Fe}(\mathrm{CN})_{6}{ }^{3-}$ can act as a flocculant to precipitate out MTAB as $\left(\mathrm{MTA}^{+}{ }_{3}\right) \mathrm{Fe}(\mathrm{CN})_{6}{ }^{3-}$ and lead to a complete removal of itself in the absence of PSS; however, nearly $70 \%$ of the added MTAB passes through coarse filtration, and reports in the filtrate. Without the addition of PSS, the process only replaces one unwanted species $\left(\mathrm{Fe}(\mathrm{CN})_{6}{ }^{3-}\right)$ with another species $(\mathrm{MTAB})$ in the solution, which is not ideal with respect to the quality of treated effluents and the substrate usage efficiency. With increasing amounts of PSS in the solution, the $\mathrm{Fe}(\mathrm{CN})_{6}{ }^{3-}$ removal efficiencies remain at a high level, but more importantly the substrate usage efficiency increases from $30 \%$ to $95 \%$ at 300 ppm PSS. The increase of this efficiency is due to the formation of PSAs by PSS and MTAB, which is also demonstrated in Figure 2. When both removal and substrate usage efficiencies reach the highest values, the polymer and surfactant dosage is at its optimum ratio. Upon further increasing the PSS concentration beyond $300 \mathrm{ppm}$, the amount of surfactant is now not enough to saturate all the PSS to form PSAs. Thus, some of the surfactant monomers are moved from the PSAs, and bound to the polymer chains in the form of polymersurfactant complexes rather than the aggregates. The polymer-surfactant complex is not as effective as the PSA in binding $\mathrm{Fe}(\mathrm{CN})_{6}{ }^{3-}$ ions, because its overall charge is almost neutralised by the monomers. Therefore, the removal efficiency of $\mathrm{Fe}(\mathrm{CN})_{6}{ }^{3-}$ decreases rapidly at this point.

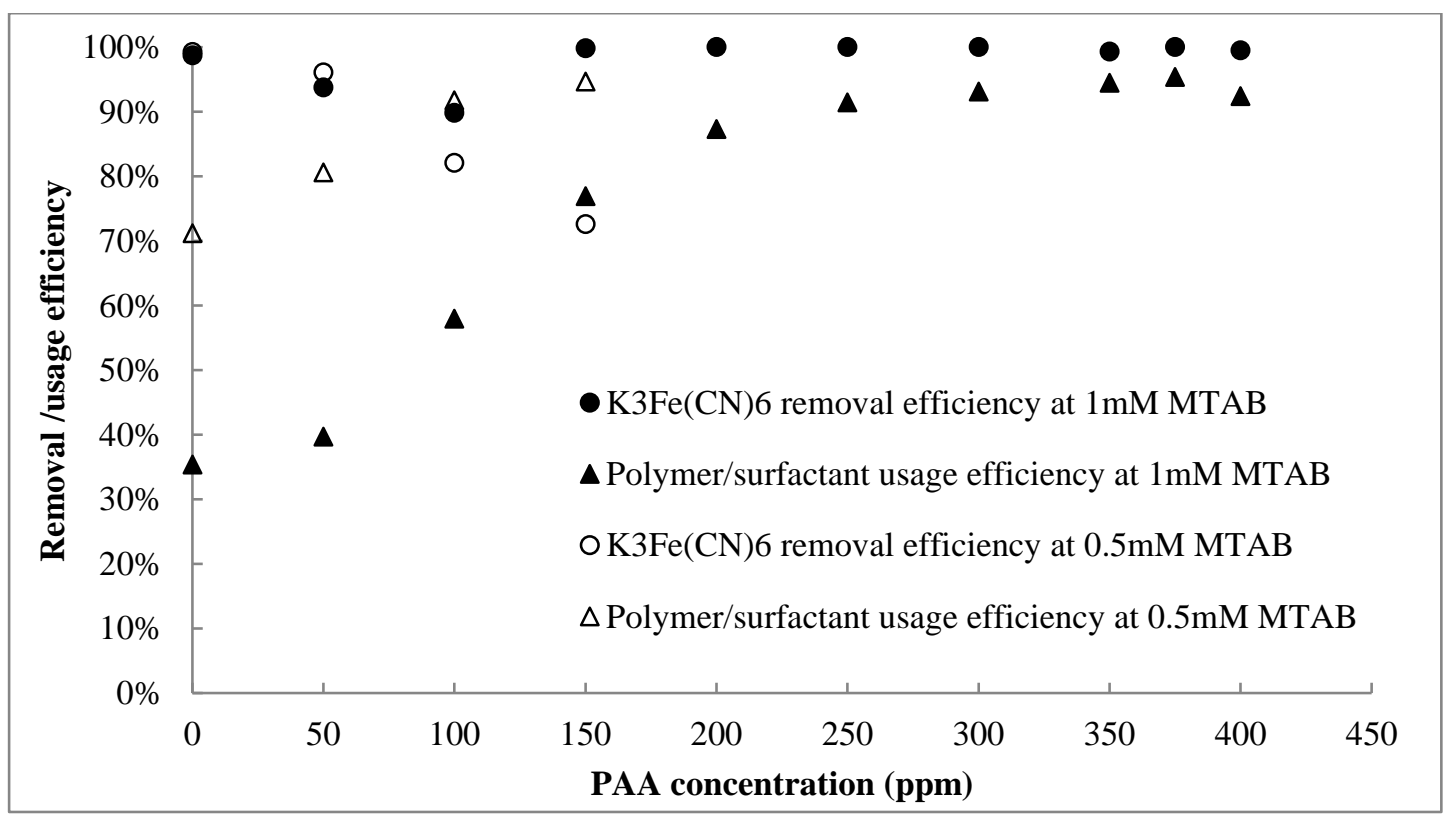

Figure 6: Dosage optimisation for $0.5 \mathrm{mM}$ and $1 \mathrm{mM}$ MTAB with various amounts of PAA to remove $0.1 \mathrm{mM} \mathrm{K}_{3} \mathrm{Fe}(\mathrm{CN})_{6}$. 
With regard to the PAA-MTAB system, the removal performance of $\mathrm{Fe}(\mathrm{CN})_{6}{ }^{3-}$ is broadly similar to that for the PSS-MTAB system. The major difference is that the dissociation and hence charge fraction of the weakly acidic PAA strongly depends on the $\mathrm{pH}$ of the solution, which can be used to manipulate the charge density and the interactions between PAA and MTAB. This manipulation may be key to the recycling of the polymer and surfactant. Therefore, the focus of this paper is the weak acid polymer: PAA. In Figure 6, $0.5 \mathrm{mM}$ and 1mM MTAB are tested with various amounts of PAA without adjusting the $\mathrm{pH}$. Without any addition of PAA, at $0.5 \mathrm{mM} \mathrm{MTAB}$, almost $100 \%$ of $\mathrm{Fe}(\mathrm{CN})_{6}{ }^{3-}$ and $70 \%$ of MTAB are retained by the filter in the form of the $\mathrm{Fe}(\mathrm{CN})_{6}{ }^{3-} \mathrm{MTAB}$ precipitates. In other words, $30 \%$ of the MTAB passes into the filtrate as an unwanted species. Interestingly, with increasing PAA concentration to $150 \mathrm{ppm}$, the removal efficiency decreases from $100 \%$ to $70 \%$, because some of the MTAB that was used to form the $\mathrm{Fe}(\mathrm{CN})_{6}{ }^{3-}-\mathrm{MTAB}$ precipitates is now bound with the PAA. Thus, the remaining MTAB monomers are insufficient to form precipitates with all of the $\mathrm{Fe}(\mathrm{CN})_{6}{ }^{3-}$.

At a higher MTAB concentration (1mM), the decrease in the initial removal efficiency still occurs for the same reason as that in the $0.5 \mathrm{mM}$ MTAB curve. However, upon further increase of the PAA concentration, the removal efficiency returns to above $99 \%$, and the main removal mechanism has probably now shifted from precipitating with the MTAB to electrostatic binding with the PSAs. The substrate usage efficiency gradually increases with the increase of PAA concentration, until reaching a plateau at $350 \mathrm{ppm}$; after that, the PAA-MTAB ratio is not optimal for the formation of PSAs to bind the anions. The molar ratio of PAA to MTAB (4.5:1) seems rather high in terms of the PAA usage, because the PAA is not fully dissociated or charged in the original solution $(\sim \mathrm{pH} 4)$ without adjusting the $\mathrm{pH}$, and only the charged segments in PAA can electrostatically interact with the MTAB. Thus, increasing the charge fraction of PAA by adjusting the $\mathrm{pH}$ is a way to reduce the PAA usage. 


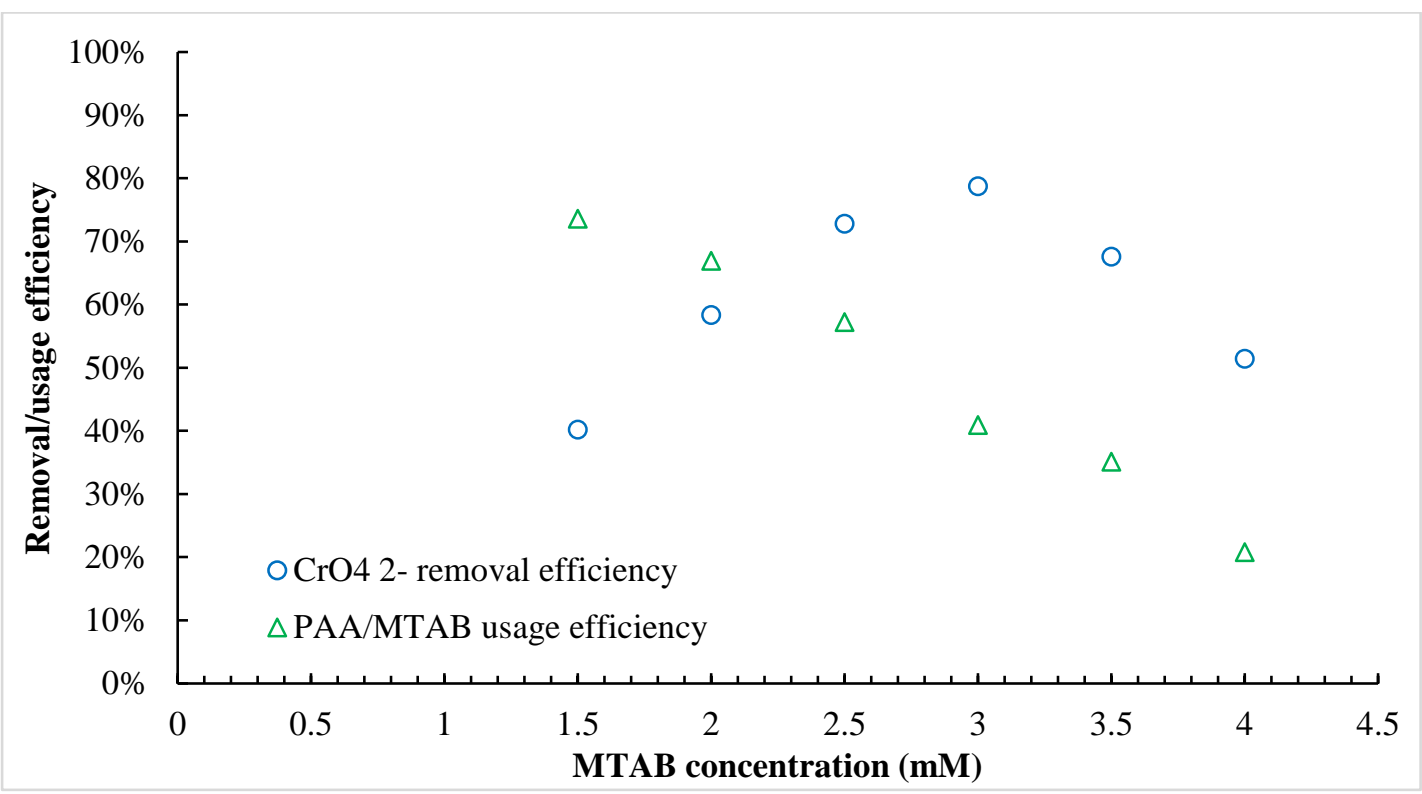

Figure 7: Dosage optimisation for 100 ppm PAA with various amounts of MTAB to remove $0.2 \mathrm{mM}$ $\mathrm{K}_{2} \mathrm{CrO}_{4}$ at $\mathrm{pH} 5.3$.

$\mathrm{CrO}_{4}{ }^{2-}$ is also removed in the PAA-MTAB system. The charge density of the chromate group is lower than that of the $\mathrm{Fe}(\mathrm{CN})_{6}{ }^{3-}$ group, which results in a relatively weak binding strength to MTAB. For this reason, without increasing the charge fraction of PAA, only $5 \%$ of the $0.2 \mathrm{mM}$ chromate is removed at the optimum dosage which would apply for removing $0.1 \mathrm{mM} \mathrm{Fe}(\mathrm{CN}) 6^{3-}(350$ ppm PAA and $1.5 \mathrm{mM}$ MTAB in Figure 6). In order to increase the dissociation and charge fraction of the PAA, the pH of the original solution is increased from 4 to 5.3 to disassociate PAA above $90 \%$, as the pKa value of PAA is 4.2. This value means that $50 \%$ of the PAA is disassociated at $\mathrm{pH} 4.2$, and $90 \%$ at $\mathrm{pH} 5.2$. When most of the PAA is negatively charged, the maximum chromate removal efficiency increases from $5 \%$ to approximately $80 \%$ when using only 100 ppm PAA (see Figure 7). The plot of removal efficiency suggests that the dosage for removing $0.2 \mathrm{mM}$ chromate is possibly $100 \mathrm{ppm}$ PAA and $3.0 \mathrm{mM}$ MTAB (Figure 7). However, when reaching this MTAB concentration, the substrate usage efficiency is only $40 \%$ and the substrate usage efficiency has already dropped considerably. Therefore, it might be preferable to lower the MTAB concentration. It is worth noting that, after adjusting the $\mathrm{pH}$, the PAA usage decreases from $350 \mathrm{ppm}$ to $100 \mathrm{ppm}$, owing to the increased dissociation and hence charge fraction. The calculated results from MTAB titration and total carbon analysis in the filtrate suggest that almost all carbon leakage originates from the MTAB monomers, which have a concentration of 
about $1.2 \mathrm{mM}$. Indeed, this leakage at $100 \mathrm{ppm}$ PAA is probably equivalent to the CFC; note the CFC seems to be about 1.2-1.4 $\mathrm{mM}$ in the 200 ppm PAA differential conductivity curve (Figure 4).

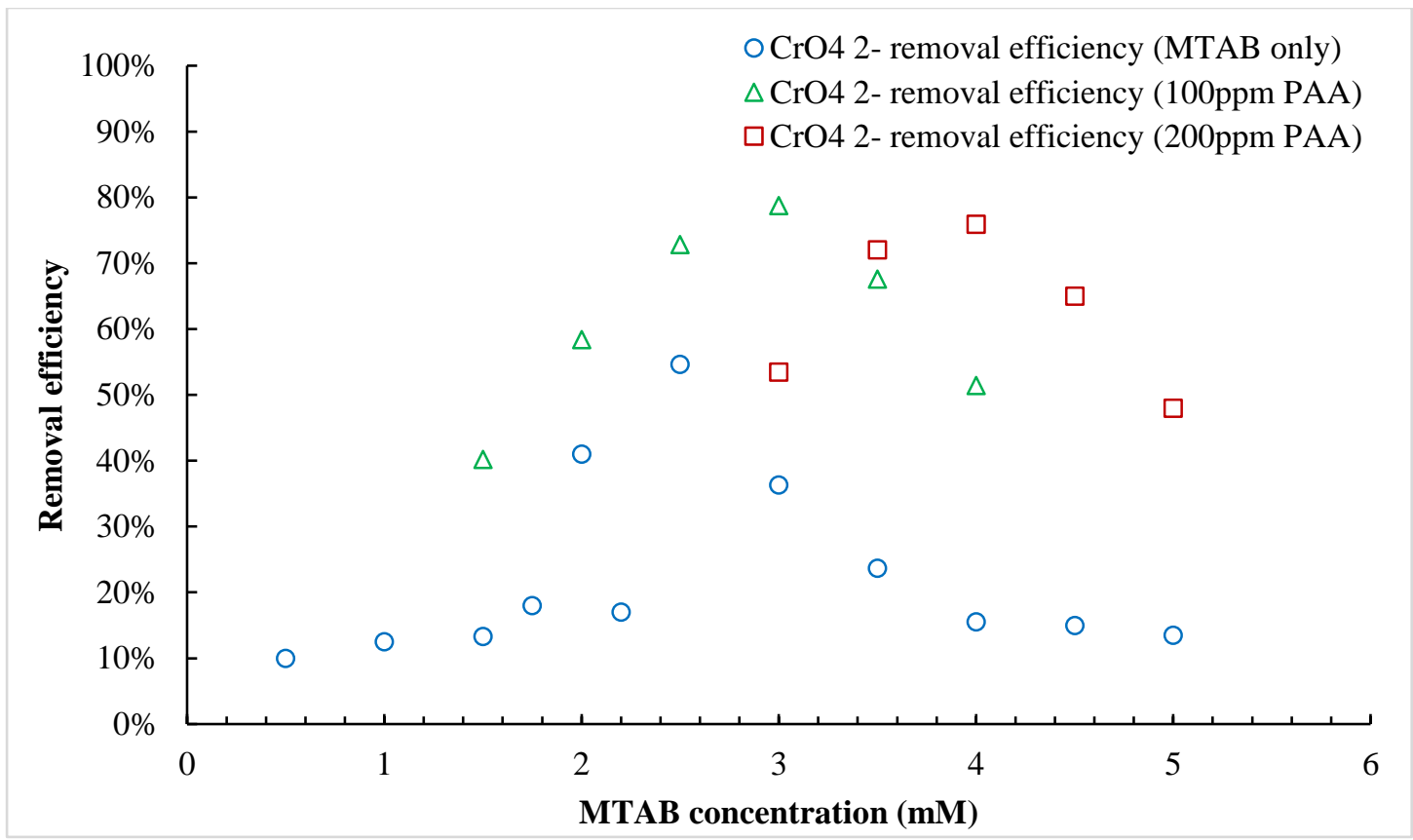

Figure 8: Effects of different PAA dosages and varying amounts of MTAB on the removal efficiency of $0.2 \mathrm{mM} \mathrm{K}_{2} \mathrm{CrO}_{4}$ at $\mathrm{pH} 5.3$.

Due to the incomplete removal of chromate at 100 ppm PAA, a higher dosage of PAA (200ppm) is tested with MTAB to understand the effects of the total amount of PSAs on the chromate removal efficiency, and to confirm the correlation between the leaked (filtrate) MTAB concentration and its CFC. In Figure 8, the maximum removal efficiency $(\sim 80 \%)$ at 200 ppm PAA is almost the same as it is at $100 \mathrm{ppm}$ PAA.

At the highest removal efficiency for both the $100 \mathrm{ppm}$ and $200 \mathrm{ppm}$ plots, most of the PAA is saturated to form PSAs (Figure 8). If the removal efficiency plot for $100 \mathrm{ppm}$ PAA is moved to the right by $1 \mathrm{mM}$, it superimposes on the plot for $200 \mathrm{ppm}$ PAA. This may well suggest that the extra 100 ppm PAA consumes an extra 1mM MTAB to form the extra amount of PSAs; however, these PSAs do not increase the removal efficiency, only the total amount of removal agent (PSA). Thus, the incomplete removal of chromate at the maximum is not caused by the quantity of available PSAs. The possible cause for this incomplete removal is discussed in detail in the section on removal limits (Section 3.4). 
In the absence of PAA, less than $60 \%$ of the chromate is also removed after coarse filtration, but more than $95 \%$ of the added MTAB reports in the filtrate (Figure 8). This removal is caused by the same reason (precipitation) as in the $\mathrm{Fe}(\mathrm{CN})_{6}{ }^{3-}-\mathrm{MTAB}$ system, but the removal efficiency of chromate is lower as a result of its lower charge density. The MTAB leakage is then severe (95\%), but can be reduced to $30 \%$ with the addition of PAA. One way of further reducing the leakage of MTAB is to decrease its CFC by increasing the charge fraction of PAA, which is discussed further in Sections 3.4 and 3.5.

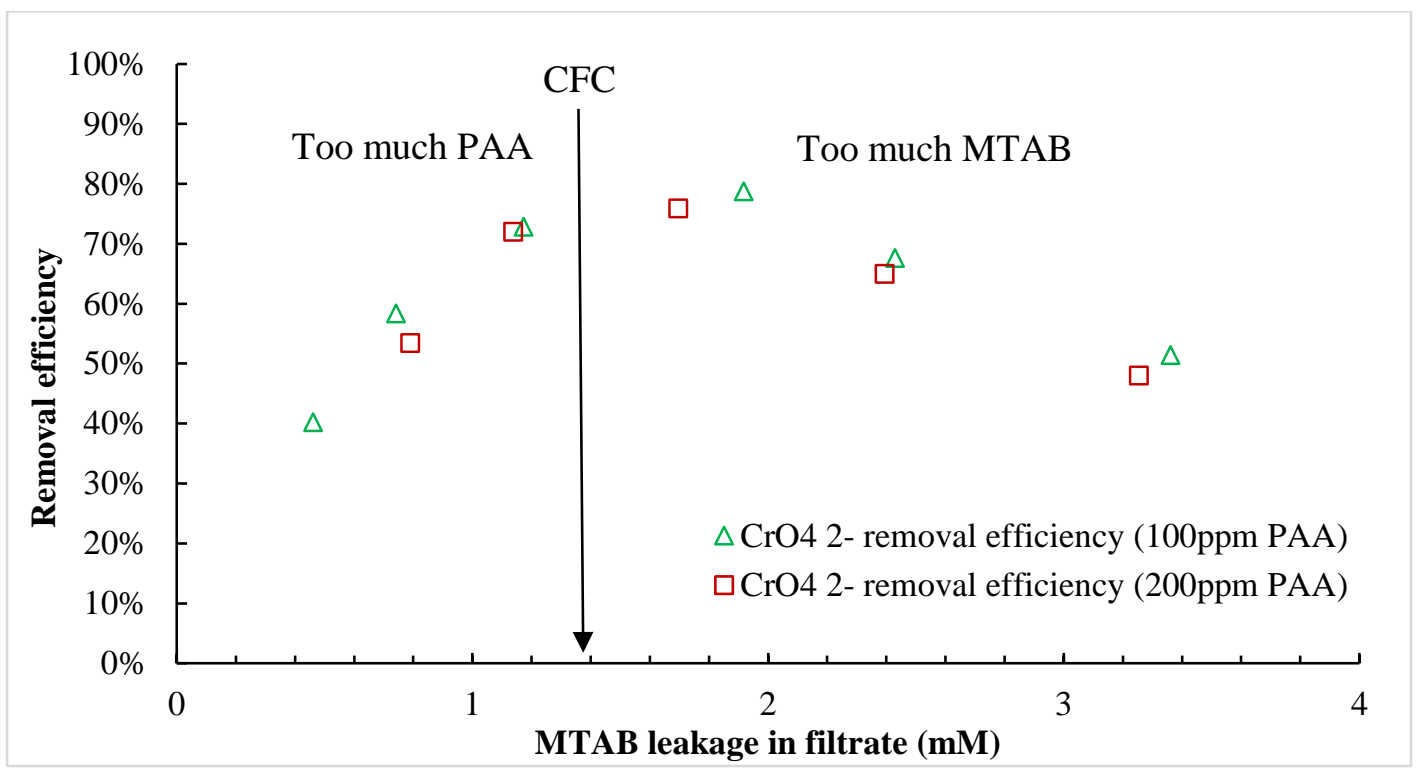

Figure 9: Correlations between the MTAB leakage in the filtrate and the $\mathrm{CrO}_{4}{ }^{2-}$ removal efficiency at 100/200 ppm PAA at pH 5.3.

To further confirm that the extra amount of PSAs have little effect on the chromate removal above a certain level, the removal efficiencies are plotted against the concentration of leaked MTAB in the filtrate (Figure 9). From conductivity measurements, the CFC of MTAB in 200 ppm PAA is approx. $1.4 \mathrm{mM}$ (Figure 4), which is also the concentration of the leaked MTAB at the highest removal efficiency for both 100 ppm and 200 ppm PAA systems (see the arrow in Figure 9). Assuming the change in MTAB monomer concentration across the coarse filter is negligible, the concentration of the leaked MTAB should be equal to the concentration of free (monomeric) MTAB in the bulk solution. At the highest removal efficiency, the amount of MTAB is just enough to saturate most of the PAA chains to form PSAs, and the monomer concentration thus equals the CFC (1.4 mM). This also confirms 
the previous interpretation of the differential change in conductivity versus differential change in surfactant concentration for the PAA-MTAB system.

When the MTAB leakage is lower than the CFC, this indicates that an excessive amount of PAA has formed polymer-surfactant complexes and these have consumed the MTAB that might otherwise leak into the filtrate. It is worth noting that, even when the leaked MTAB concentration is slightly below the CFC, PSAs can still form when the local concentration (near the oppositely charged PAA chain) of MTAB is above the CFC under the electrostatic and hydrophobic interactions. At lower MTAB concentrations, the interactions become too weak to allow this. Therefore, some of the chromate is removed when the leaked MTAB concentration is lower than its CFC, and the removal efficiency rapidly decreases with decreasing MTAB leakage. On the other hand, when the leakage is higher than the CFC, the excessive amount of MTAB now present leaks directly into the filtrate. The decreasing chromate removal efficiency probably results from charge imbalance and the competitive binding between PSAs and micelles. The latter may bind some chromate ions and pass through the coarse filter..

In conclusion, an extra amount of PSAs above a critical amount does not further increase the removal efficiency of chromate, and the high removal is mainly due to binding with the PSAs rather than to precipitation with the MTAB.

\subsection{Filtration method}

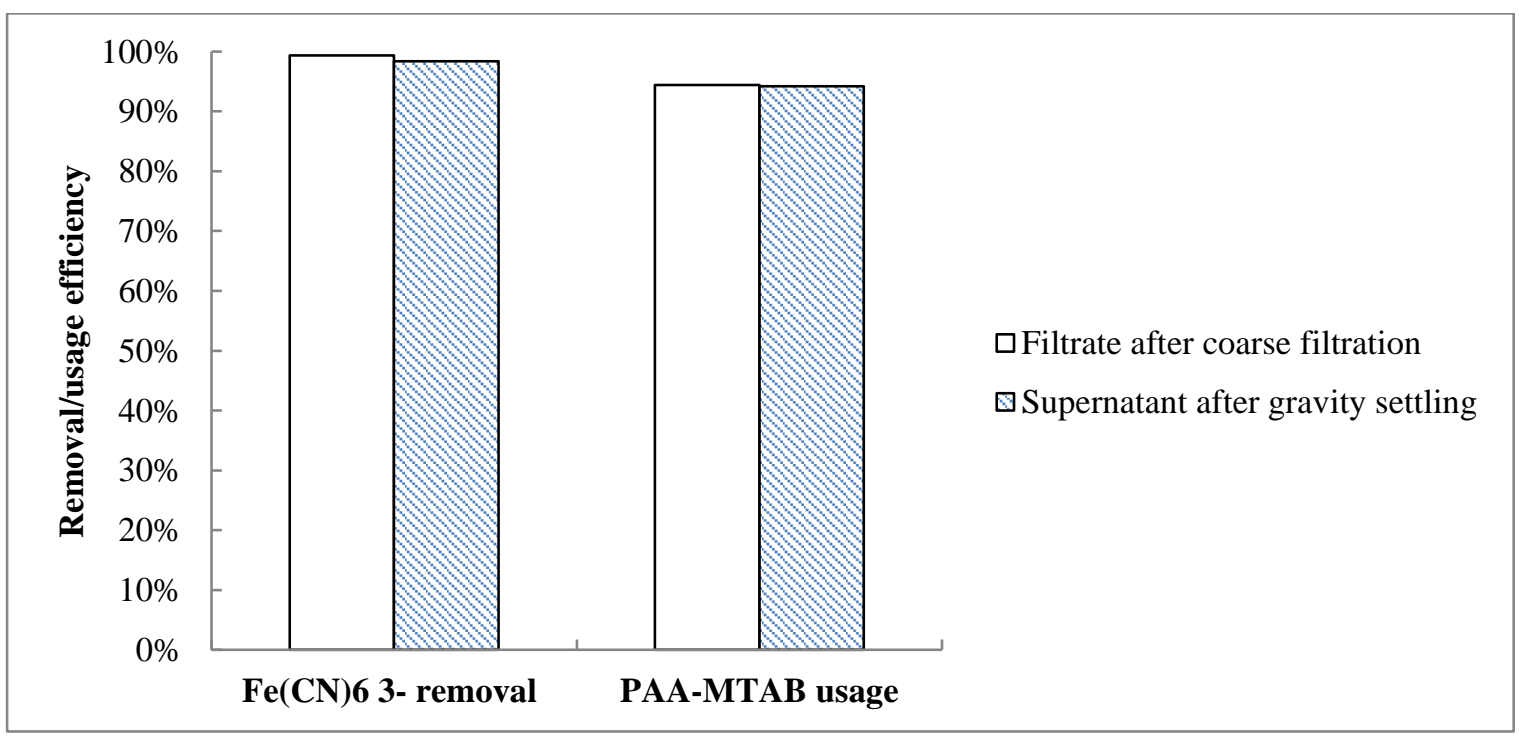


Figure 10: Effects of coarse filtration and gravity settling on $\mathrm{Fe}(\mathrm{CN})_{6}{ }^{3-}$ removal and substrate usage efficiencies at the optimum dosage (350 ppm PAA +1 mM MTAB).

The treatment outcome for removing $\mathrm{Fe}(\mathrm{CN})_{6}{ }^{3-}$ is almost the same after either coarse filtration or gravity settling (Figure 10). The advantage of gravity settling is that it consumes less energy. The $\mathrm{Fe}(\mathrm{CN})_{6}{ }^{3-}$ ions have a high charge density. This allows them to be removed effectively as a targeted contaminant, and to enhance the speed and effectiveness of the flocculation of PSAs. This synergistic effect can obviate the need for filtration, which further increases the speed of the process, and subsequently increases the treatment capacity.

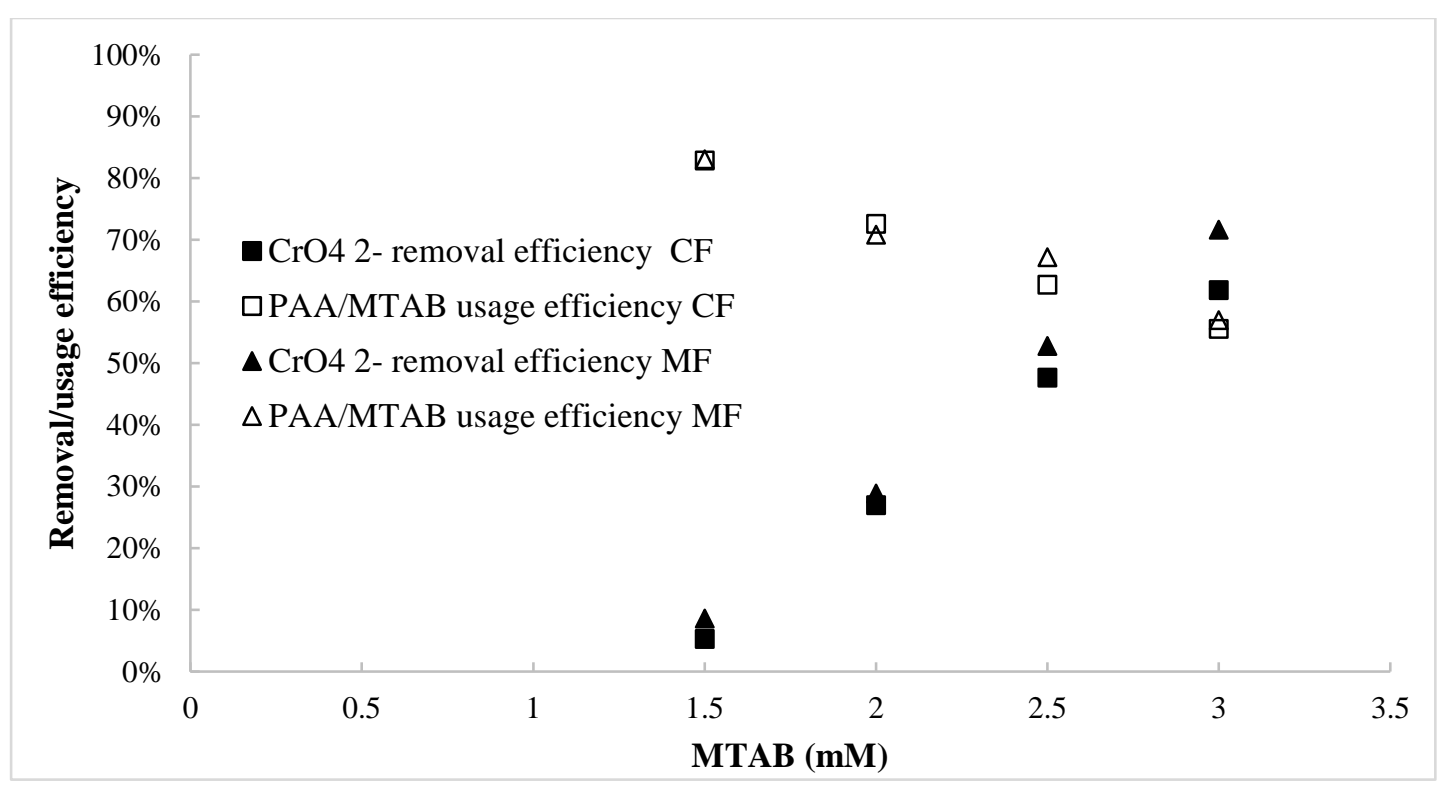

Figure 11: Effects of microfiltration (MF) and coarse filtration (CF) on the removal efficiency of 0.2 $\mathrm{mM} \mathrm{K} \mathrm{CrO}_{4}$ and the usage efficiency of 100 ppm PAA with various amounts of MTAB.

For chromate removal, owing to the relatively low charge density, the synergistic effect described above in the system is weaker. The chromate flocculated solutions are filtered by both micro-filtration and coarse filtration, respectively. In Figure 11, the results show that nevertheless there is little difference in removal and substrate usage efficiencies for the two filtration methods, due to the size of most of the flocs beinglarger than the pore size of the coarse filter $(20 \mu \mathrm{m})$. Furthermore, a coarse filter is capable of separating the flocs from the solution with a lower filtration time and energy consumption than using microfiltration. 
In short, the use of either coarse filtration or gravity settling for rapid separation depends upon the charge density of anions. If the targeted anion possesses a high charge density (eg it is trivalent), a gravity settling process may be applied. Otherwise, a step of coarse filtration would be recommended as a mean of separation.

3.4 Removal limit and capacity

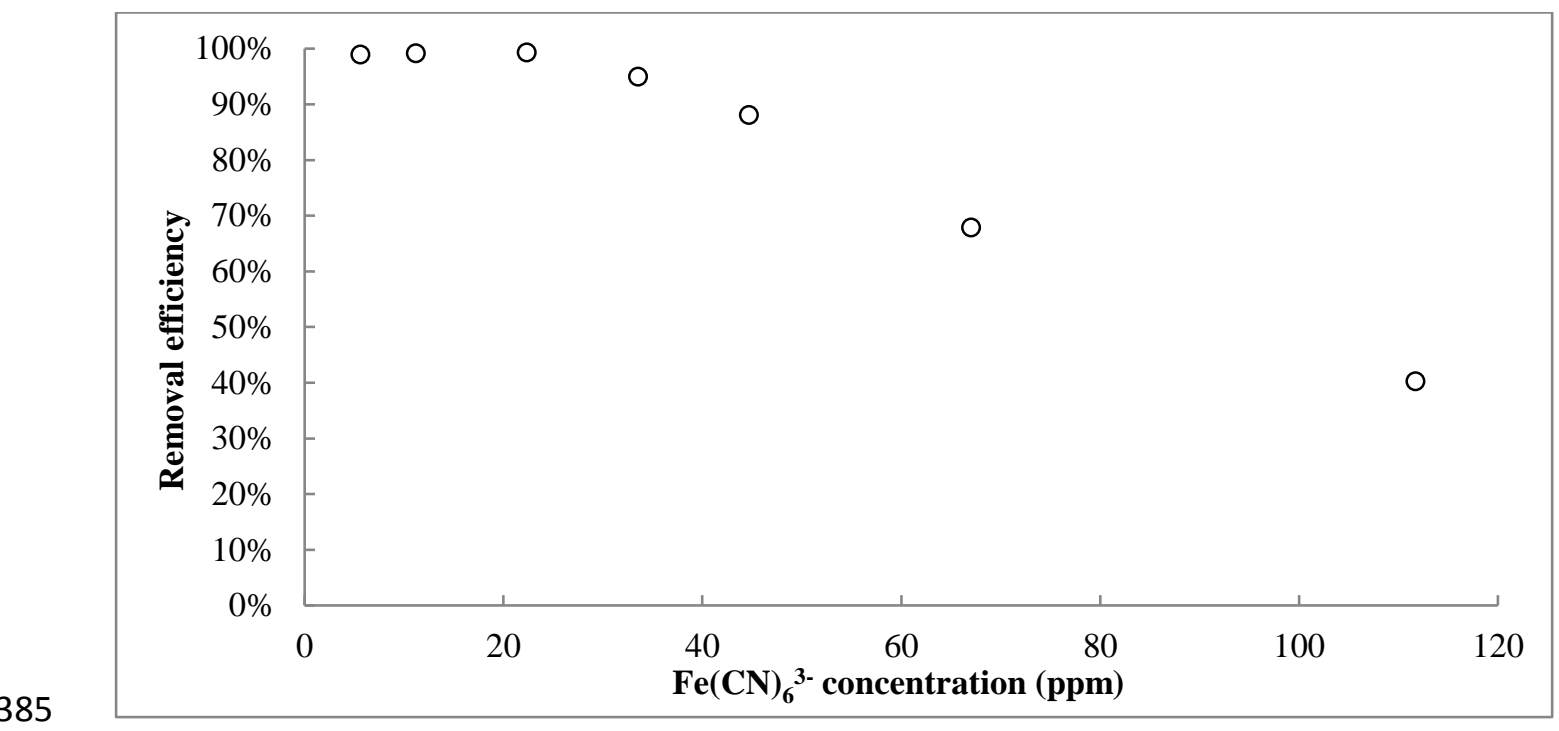

Figure 12: $\mathrm{Fe}(\mathrm{CN})_{6}{ }^{3-}$ removal efficiency at the optimum dosage (350 ppm PAA $+1 \mathrm{mM}$ MTAB).

With regard to the $\mathrm{Fe}(\mathrm{CN})_{6}{ }^{3-}-\mathrm{PAA}-\mathrm{MTAB}$ system, the removal efficiency of $\mathrm{Fe}(\mathrm{CN})_{6}{ }^{3-}$ starts to decrease as the $\mathrm{Fe}(\mathrm{CN})_{6}{ }^{3-}$ concentration rises slightly above $20 \mathrm{ppm}$, and gradually decreases with increasing $\mathrm{Fe}(\mathrm{CN})_{6}^{3-}$ concentration (Figure 12). This suggests that the adsorption capacity of PSAs at the optimum dosage is limited. From measurements of the $\mathrm{Fe}(\mathrm{CN})_{6}{ }^{3-}$ concentration in the filtrate, the PSAs can effectively remove $\mathrm{Fe}(\mathrm{CN})_{6}{ }^{3-}$ from solution down to a concentration of $10 \mathrm{ppb}$. 


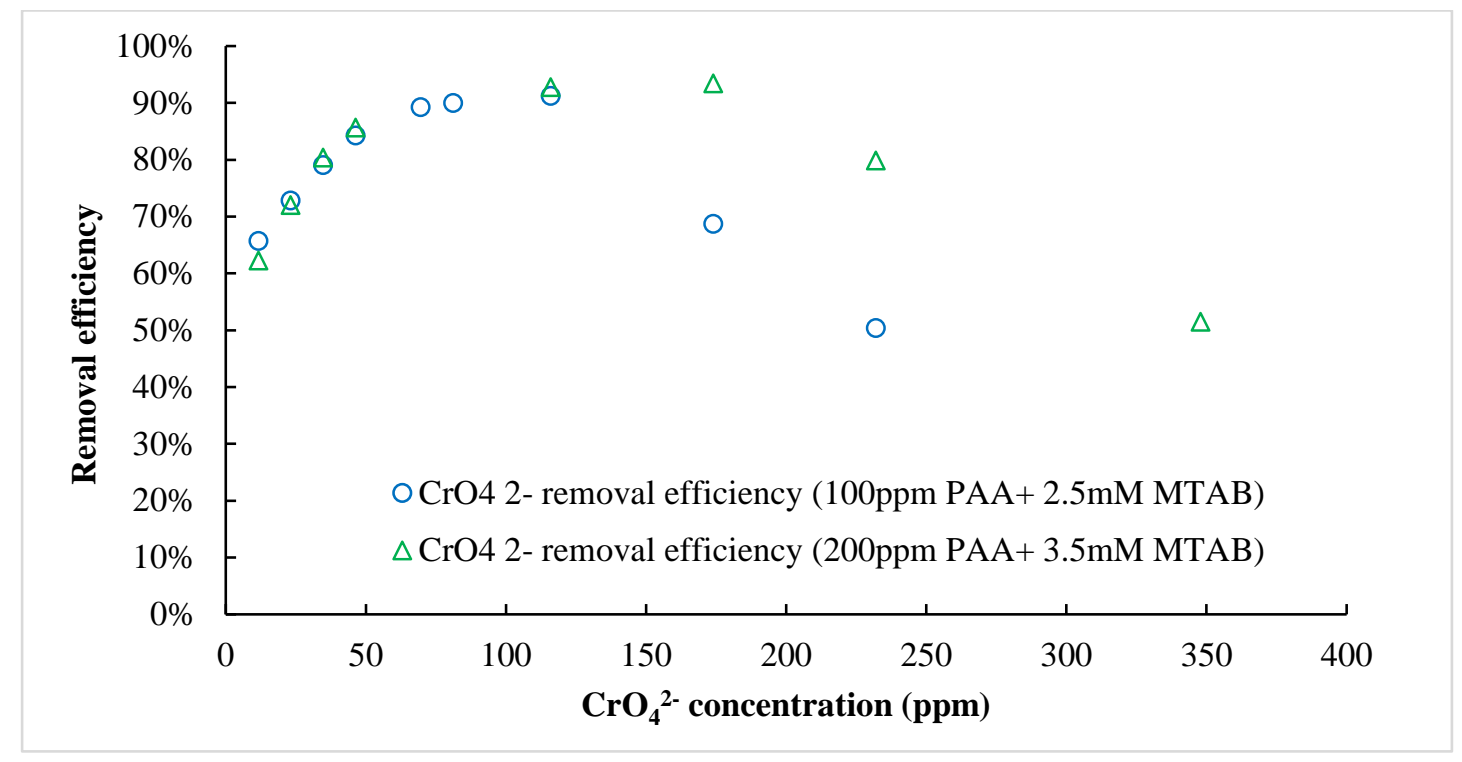

Figure 13: Removal efficiency of $\mathrm{CrO}_{4}{ }^{2-}$ at two possible dosages of PAA and MTAB with increasing concentrations of $\mathrm{K}_{2} \mathrm{CrO}_{4}$.

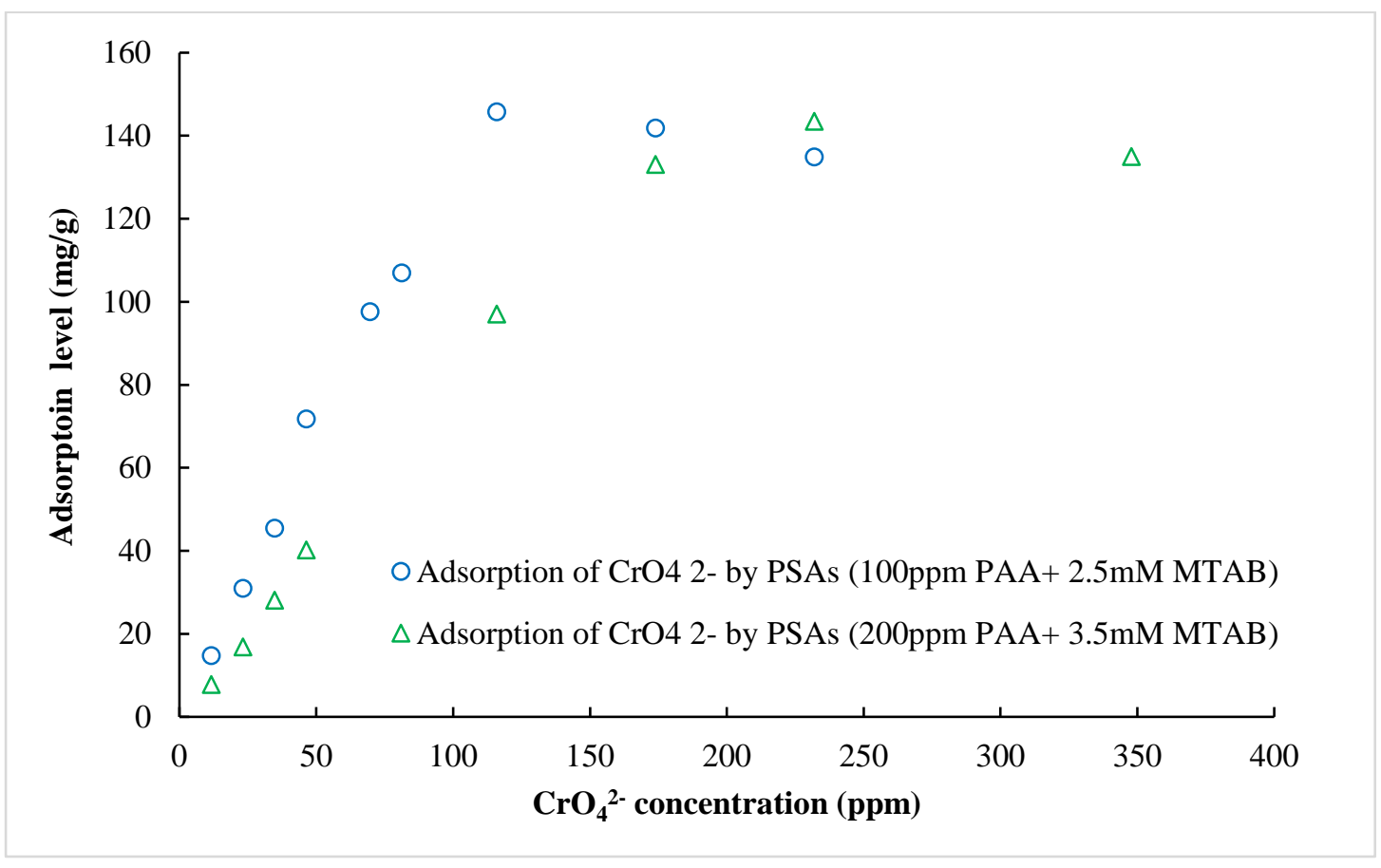

Figure 14: Adsorption level of $\mathrm{CrO}_{4}{ }^{2-}$ at two possible dosages of PAA and MTAB with increasing concentrations of $\mathrm{K}_{2} \mathrm{CrO}_{4}$. 


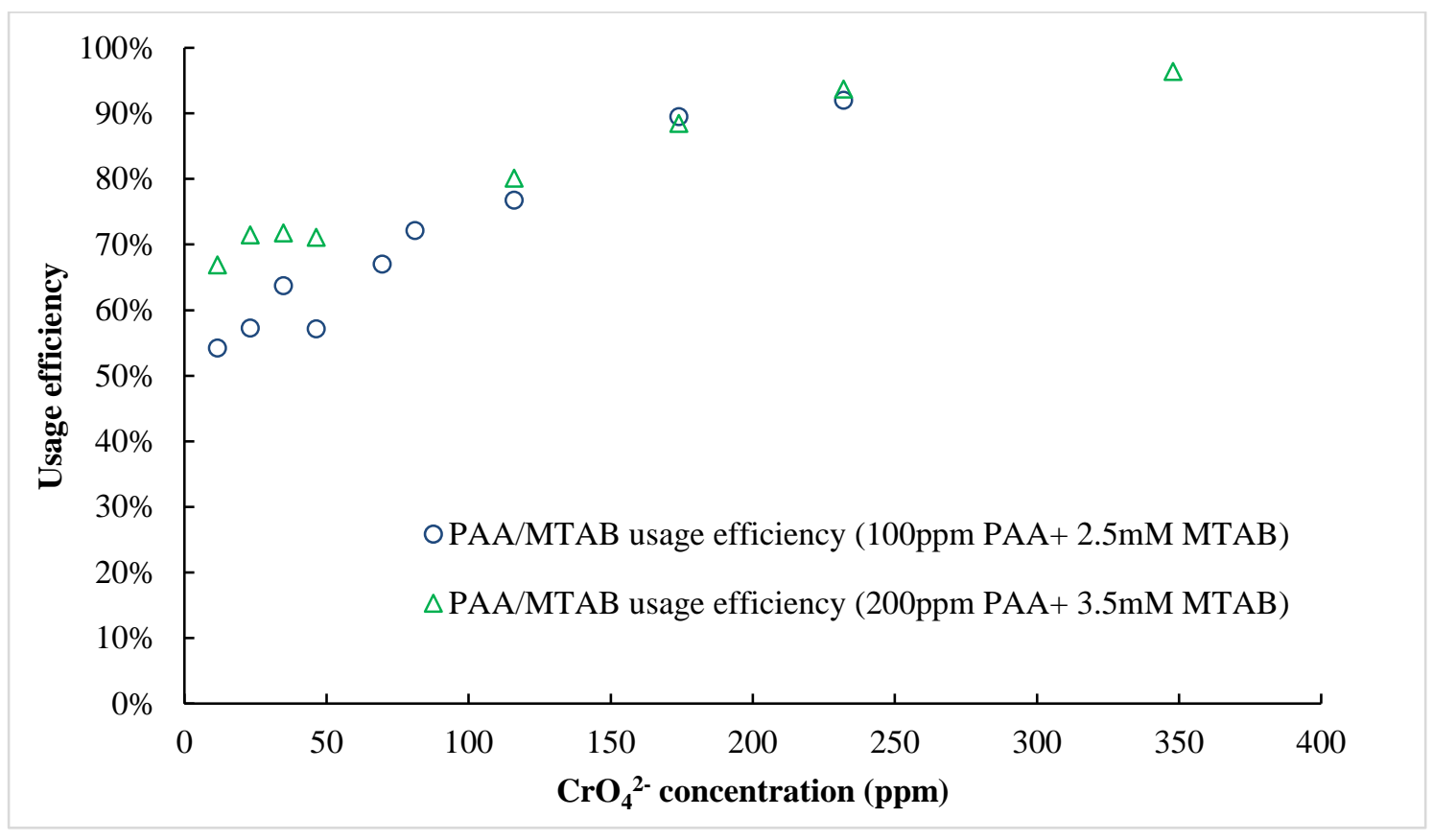

Figure 15: Usage efficiency of PAA and MTAB at two possible dosages of PAA and MTAB with increasing concentrations of $\mathrm{K}_{2} \mathrm{CrO}_{4}$.

With regard to the $\mathrm{K}_{2} \mathrm{CrO}_{4}-\mathrm{PAA}-\mathrm{MTAB}$ system, with increasing chromate concentrations, the chromate removal efficiency at 100 ppm PAA firstly increases to above $90 \%$, peaks at 70 ppm chromate and finally decreases quickly (Figure 13). The reason for the initial increase of removal efficiency is that, before reaching the saturation point (i.e. the peak), the added chromate concentration is increased but the concentration of chromate in the filtrate remains at the removal limit level. Defining the 'removal limit' as the minimum concentration of contaminant ions which can be treated, and since chromate has a relatively low charge density, the removal limit of PSAs for chromate is relatively high at $7 \mathrm{ppm}$ when compared with $10 \mathrm{ppb}$ for the $\mathrm{Fe}(\mathrm{CN})_{6}{ }^{3-}$. The subsequently decreasing in the removal efficiency is due to the limited adsorption capacity of the PSAs. This capacity limits the removal efficiency at a high concentration of contaminant ions.

In Figure 13, the removal efficiency for the 200 ppm PAA system continues to increase until the chromate feed concentration reaches $\sim 174 \mathrm{ppm}$, which is about twice as high as that seen in the 100 ppm PAA system. The results of adsorption level in Figure 14 show that both 100 ppm and 200 ppm PAA systems level off at the same amount of chromate adsorption per gram of PSA ( 140 mg/g), and the 100 ppm PAA curve reaches the plateau first, which indicates the PSAs are saturated first. This is 
useful for determining suitable polymer and surfactant dosages to remove a certain amount of contaminants. A larger amount of polymer and surfactant is required to remove a higher concentration of contaminant ions, and the surfactant dosage should be just enough to saturate the polymer to form PSAs.

Another important change with increasing $\mathrm{K}_{2} \mathrm{CrO}_{4}$ concentration is the increase of ionic strength, which increases the substrate usage efficiency (Figure 15). At higher ionic strength, the screening of electrostatic repulsive forces between monomers in aggregates promotes the formation of PSAs at a lower MTAB concentration, in the same way that the $\mathrm{CMC}$ is lowered by increasing ionic strength. In addition, the coagulation and flocculation process is promoted by higher ionic strength. Therefore, the substrate usage efficiency may be higher for real waste streams than for the synthetic ions made from deionized water, as a result of a higher ionic strength.

\subsection{Effects of $\mathrm{pH}$ on removal efficiency}

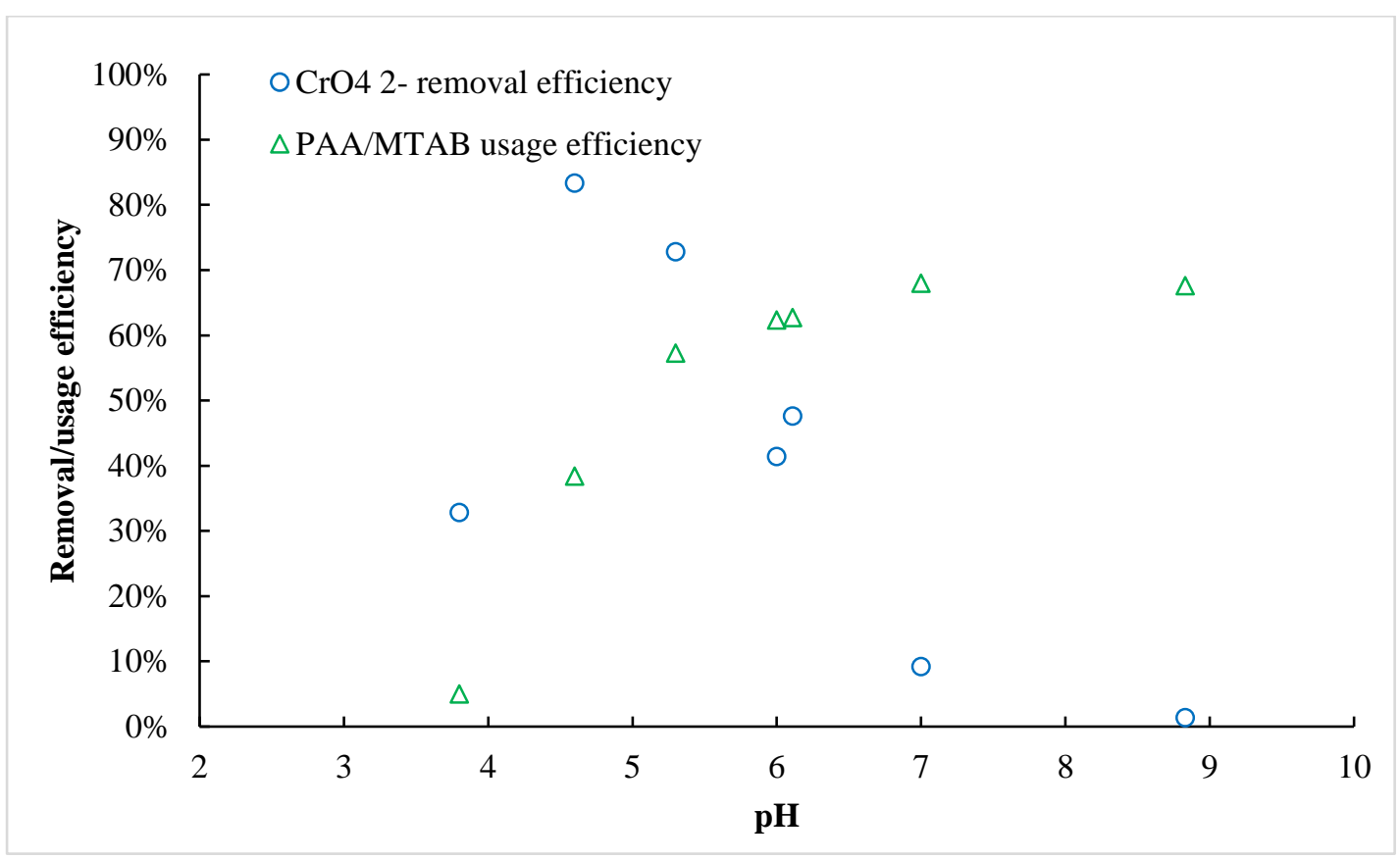

Figure 16: Removal efficiency of $0.2 \mathrm{mM} \mathrm{K}_{2} \mathrm{CrO}_{4}$ and the usage efficiency of 100 ppm PAA and 2.5 mM MTAB at different $\mathrm{pH}$ values.

The effective $\mathrm{pH}$ range for chromate removal in the PAA-MTAB system is relatively narrow $(\mathrm{pH}$ 4.5-6; see Figure 16). As a consequence of adding $100 \mathrm{ppm} \mathrm{PAA,} \mathrm{the} \mathrm{natural} \mathrm{pH}$ of the original solution is approximately 4. To enhance the formation of PSAs, hydroxide ions are added to promote the 
disassociation of PAA, and subsequently increase the charge fraction of PAA. The added hydroxide ions, however, also compete with the chromate ions in binding to the PSAs.

As chromate ions have a relatively low charge density, the changes in removal and substrate usage efficiencies are strongly related to the charge fraction of PAA. Increasing the $\mathrm{pH}$ to 6.2 means $99 \%$ of the PAA is theoretically disassociated. Therefore, the substrate usage efficiency reaches its highest value $(\sim 70 \%)$. Beyond this $\mathrm{pH}$, further increasing the $\mathrm{pH}$ has little effect on the substrate usage efficiency and the formation of PSAs (Figure 16). On the other hand, although the substrate usage efficiency increases by $5 \%$ from $\mathrm{pH} 5.3$ to 6.2 , the removal efficiency is compromised by $20 \%$. The reason for this is that the undesired competing effect of hydroxide on chromate binding is stronger than the desired disassociation of PAA, leading to a displacement of the weakly bound chromate ions by the hydroxide ions. Therefore, upon further increasing the $\mathrm{pH}$ to 7 and beyond, less than $5 \%$ chromate is now removed. A possible solution is using a weak acid polymer but possessing a lower pKa value, i.e.a more strongly acidic polymer, so that the polymer is fully charged at a moderate $\mathrm{pH}$. In conclusion, due to the relatively low charge density of chromate ions, in order to achieve a high removal efficiency, a fine balance between the extra formation of PSAs and the lower removal of chromate must be made by adjusting the $\mathrm{pH}$. In addition, $\mathrm{pH}$ adjustment can generate salt and increase the ionic strength, which may have some deleterious effects on the treatment outcome.

3.6. Effects of $\mathrm{KCl}$ and organic contaminants on the removal efficiency

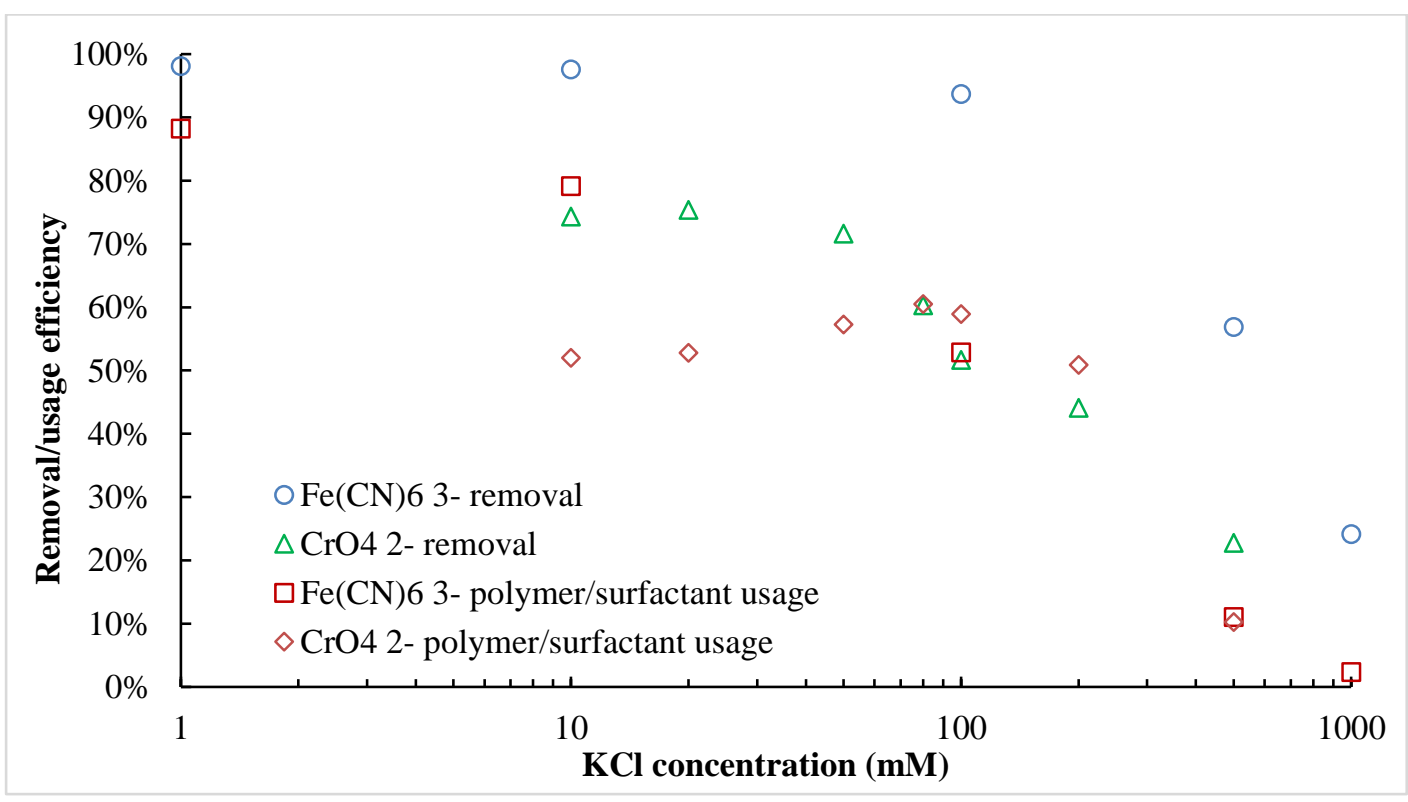


Figure 17: Removal and substrate usage efficiencies of $\mathrm{Fe}(\mathrm{CN})_{6}{ }^{3-}$ (no $\mathrm{pH}$ adjustment) and $\mathrm{CrO}_{4}{ }^{2-}$ (at $\mathrm{pH}$ 5.3) in the presence of different $\mathrm{KCl}$ concentrations at their dosages (300 ppm PSS+1.5 mM MTAB+ $0.1 \mathrm{mM} \mathrm{Fe}(\mathrm{CN})_{6}^{3-} ; 100 \mathrm{ppm} \mathrm{PAA}+2.5 \mathrm{mM} \mathrm{MTAB}+0.2 \mathrm{mM} \mathrm{CrO}_{4}{ }^{2-}$, respectively)

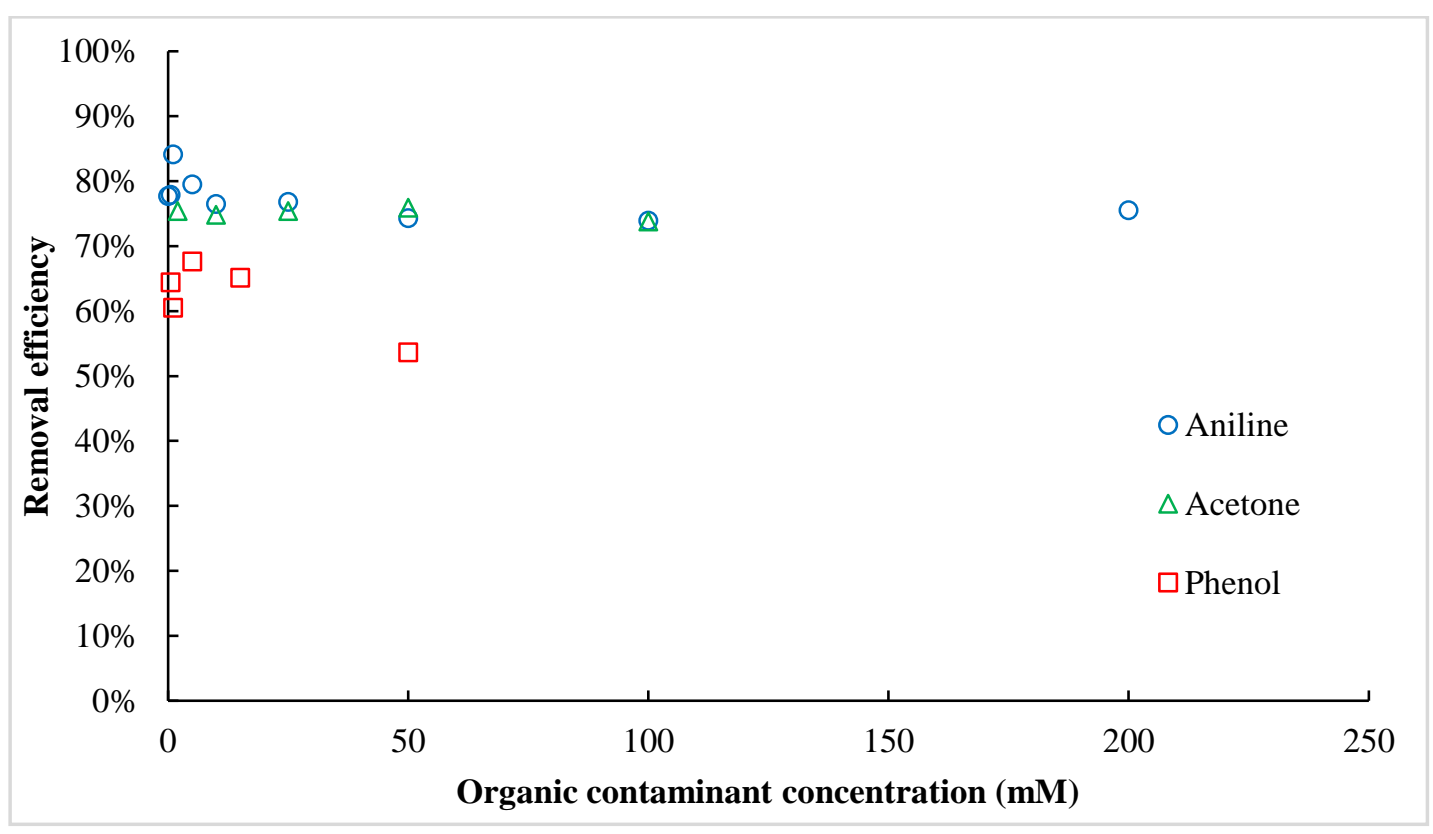

Figure 18: Removal efficiencies of $\mathrm{CrO}_{4}{ }^{2-}$ at the optimum dosage of PAA and MTAB in the presence of various organics at different concentrations.

The effects of salinity and organic contaminants on the treatment performance for metallic anion removal are studied. Organic contaminants such as acetone and aniline have little effect on the process (Figure 18). However, a 20\% decrease in the removal efficiency is caused by the addition of phenol and the solution did not return to a clear state from a turbid one even after prolonged agitation. The reason might be that phenol is a relatively polar organic compound and so may interfere with the electrostatic binding or even the hydrophobic binding.

The $\mathrm{KCl}$ is used as an example salt in the solution, and the concentration is studied up to $1 \mathrm{M} \mathrm{KCl}$, which is relatively high for industrial effluents. Note that sea water salinity on average is around $0.5 \mathrm{M}$. In the $\mathrm{Fe}(\mathrm{CN})_{6}^{3-}$ system, the substrate usage efficiency decreases rapidly above $50 \mathrm{mM} \mathrm{KCl}$, but the removal efficiency only starts to drop at around $100 \mathrm{mM} \mathrm{KCl}$ (Figure 17). The delayed decrease in the removal efficiency may be caused by the unbound surfactant monomers forming $\mathrm{Fe}(\mathrm{CN})_{6}{ }^{3-}$-MTAB precipitates at higher salinity - a 'salting out' effect. In the chromate system, the removal efficiency 
starts to decrease around $50 \mathrm{mM} \mathrm{KCl}$, so the chromate system is less resistant to salinity effects than the $\mathrm{Fe}(\mathrm{CN})_{6}^{3-}$ system. Interestingly, the substrate usage efficiency increases slightly until $100 \mathrm{mM}$, before decreasing with further addition of $\mathrm{KCl}$. This initial increase is probably due to the decrease of the CFC in a solution of moderately high ionic strength, which promotes the formation of PSAs at a lower surfactant concentration. In short, the $\mathrm{Fe}(\mathrm{CN})_{6}{ }^{3-}$ ion possesses a higher charge density than the chromate ion, and this leads to a relatively higher tolerance to the ionic strength environment. One possible explanation is that the trivalent ion is more strongly solvated by water molecules and thus less prone to 'salting out'.

In conclusion, the polymer surfactant aggregate process works effectively for removing anions, such as metallic anions, in the presence of moderate ionic strengths and organic contaminants, and the tolerance to the ionic and organic environment increases with the charge density of the targeted anion.

3.7. Effects of temperature on the removal efficiency

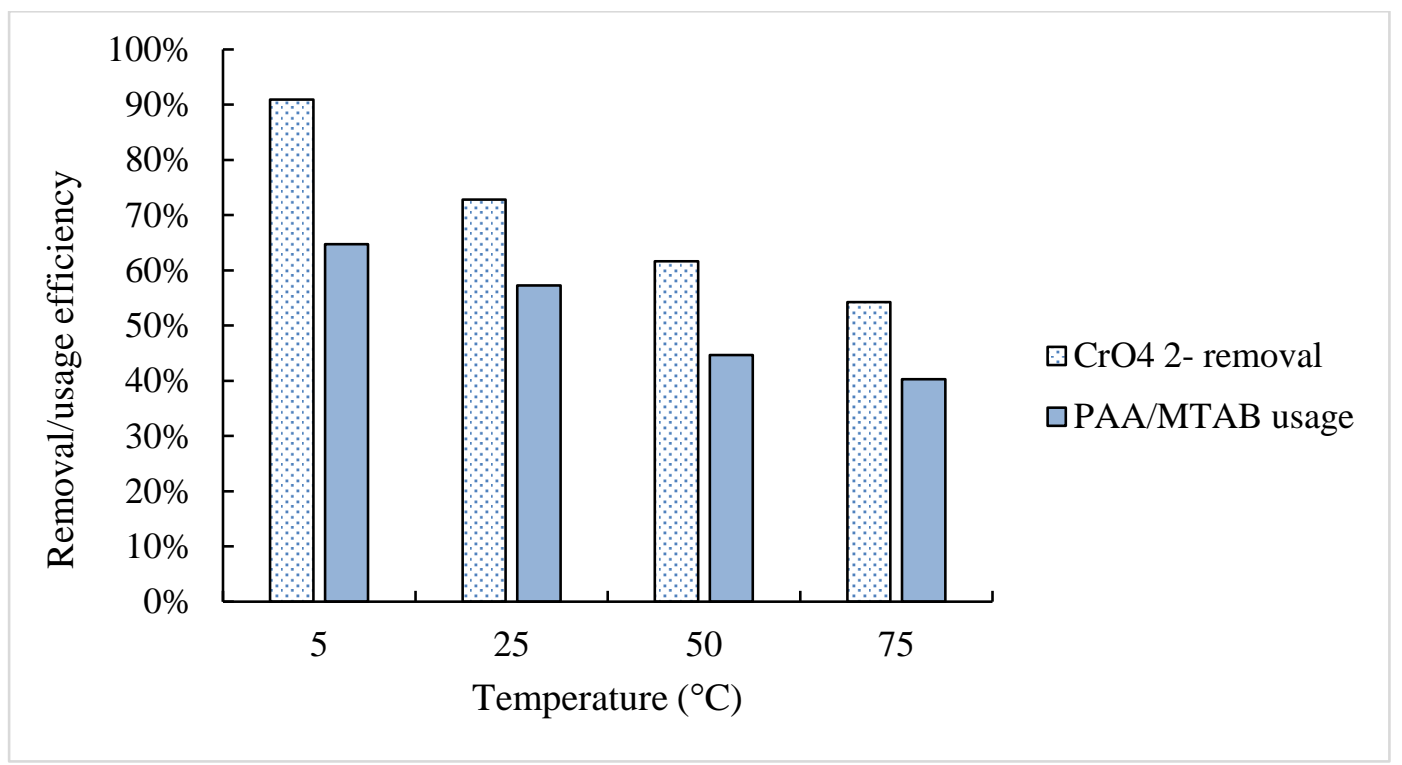

Figure 19: Temperature effects on the chromate removal and substrate usage efficiencies at the possible dosage at pH $5.3\left(100 \mathrm{ppm} \mathrm{PAA}+2.5 \mathrm{mM} \mathrm{MTAB}+0.2 \mathrm{mM} \mathrm{K}_{2} \mathrm{CrO}_{4}\right)$.

The performance and robustness of PSA treatment at different solution temperatures are studied. With increasing temperature in Figure 19, both the chromate removal and substrate usage efficiencies decrease. This is probably caused by the exothermic nature of the formation of PSAs as well as their binding with chromate ions, so that a higher temperature moderately inhibits both. Most importantly, 
the performance of PSA treatment is still high at room temperature $\left(25^{\circ} \mathrm{C}\right)$, and the extent of decrease with increasing temperature is small. By extension, the process may thus be expected to have a slightly better performance during winter than summer, since average room temperatures will fluctuate in a seasonal manner. In conclusion, the treatment process is robust over a moderate temperature range (5$\left.50{ }^{\circ} \mathrm{C}\right)$.

\section{Conclusions}

A novel effluent treatment process is reported which use uses polymer-surfactant aggregates (PSAs) to remove anions from dilute aqueous solutions. This process uses PSS or PAA as an anionic polymer and MTAB as a surfactant to form micelle-like aggregates on the polymer backbone, and then adsorb free multivalent anions, such as $\mathrm{Fe}(\mathrm{CN})_{6}{ }^{3-}$ and $\mathrm{CrO}_{4}{ }^{2-}$, onto the aggregates. At the same time, the anionbound PSAs flocculate to form larger flocs under the hydrophobic and electrostatic forces. These flocs are then separated by either gravity settling or a $20 \mu \mathrm{m}$ coarse filter from the solution. Such a polymersurfactant aggregates process is of great potential interest in the removal of dilute, negatively charged species, such as metallic or other anions, during effluent water treatment. In particular, the results have shown that:

- Plotting the conductivity as the differential change in conductivity per differential change in surfactant concentration can reveal useful details about the nature and status of the molecular interactions between polymer and surfactant, which may be helpful in determining the CFC, the $\mathrm{CMC}$, and in particular the optimum dosage to ensure high removal efficiency and high substrate usage efficiency.

- The PSAs are responsible for removing the anions from dilute aqueous solution, and the optimum removal efficiency corresponds to the maximum amount of PSAs being formed in the solution. The latter occurs around the break point in the differential conductivity curve before levelling off (point $\mathrm{C}$ in Figure 1). 
- Due to the intermolecular associations between PSAs, larger size flocs are formed in the process and are then separated from aqueous solution by a $20 \mu \mathrm{m}$ coarse filter. Gravity settling is also an effective alternative to speed up the separation process.

- $99 \%$ of $0.1 \mathrm{mM} \mathrm{Fe}(\mathrm{CN})_{6}{ }^{3-}$ is removed with 350 ppm PAA and $1 \mathrm{mM}$ MTAB. $80 \%$ of $0.2 \mathrm{mM}$ $\mathrm{CrO}_{4}{ }^{2-}$ is removed using $100 \mathrm{ppm}$ PAA and $1.5 \mathrm{mM}$ MTAB at $\mathrm{pH}$ 5.3. The dosage of polymer can be reduced, if the charge fraction of PAA is increased by $\mathrm{pH}$ adjustment.

- This process works effectively at moderate $\mathrm{pHs}(4.5-6)$ and temperatures $\left(5-50{ }^{\circ} \mathrm{C}\right)$, and can cope with the presence of moderate amounts of salt $(<0.1 \mathrm{M})$ and organic contaminants $(<50$ $\mathrm{mM})$.

\section{Symbol glossary}

$\mathrm{C}_{\text {filtrate }}$ : the concentration of anion in the filtrate (unit: ppm)

$\mathrm{C}_{\text {MTAB filtrate: }}$ the concentration of MTAB in the filtrate (unit: $\mathrm{mM}$ )

$\mathrm{C}_{\text {original effluent: }}$ the concentration of anions in the waste effluent (unit: $p$ )

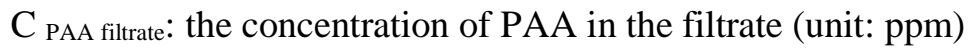

Carbon content ${ }_{\text {МТАВ: }}$ molecular weight of carbon in $\mathrm{MTAB}=204 \mathrm{~g} / \mathrm{mol}$

Carbon molecular weight by percentage PAA: the percentage of carbon in the molecular weight to the total molecular weight of each segment of PAA $=0.5$

CFC: critical formation concentration

CMC: critical micellar concentration

MTAB: myristyl trimethyl ammonium bromide

PAA: poly(acrylic acid)

PSA: polymer surfactant aggregate

PSS: poly(sodium 4-styrenesulfonate)

Total carbon added removal agent: the total carbon mass concentration of the added removal agent (polymer and surfactant) (unit: ppm)

Total carbon ${ }_{\text {filtrate: }}$ the total mass concentration of carbon in the filtrate (unit: ppm) 
We acknowledge the support of the Singapore-Peking-Oxford Research Enterprise which is a collaborative funding scheme between the National University of Singapore, Peking University and the University of Oxford and provided L.C Shen with a DPhil scholarship.

505 


\section{References}

[1] I.R. Higgins, Ion exchange. Present and future use, Environ. Sci. Technol., 7 (1973) 11104.

[2] T.C. Jorgensen, L.R. Weatherley, Ammonia removal from wastewater by ion exchange in 510 the presence of organic contaminants, Water Res., 37 (2003) 1723-8.

[3] K. Vaaramaa, J. Lehto, Removal of metals and anions from drinking water by ion exchange, Desalination, 155 (2003) 157-70.

[4] B. Gözmen, M.A. Oturan, N. Oturan, O. Erbatur, Indirect Electrochemical Treatment of Bisphenol A in Water via Electrochemically Generated Fenton's Reagent, Environ. Sci. 515 Technol., 37 (2003) 3716-23.

[5] Y.-h. Xu, T. Nakajima, A. Ohki, Adsorption and removal of arsenic(V) from drinking water by aluminum-loaded Shirasu-zeolite, J. Hazard. Mater., 92 (2002) 275-87.

[6] C. Boukhalfa, Sulfate removal from aqueous solutions by hydrous iron oxide in the presence of heavy metals and competitive anions: Macroscopic and spectroscopic analyses, 520 Desalination, 250 (2010) 428-32.

[7] N. Hilal, G. Busca, F. Rozada, N. Hankins, Use of activated carbon to polish effluent from metalworking treatment plant: comparison of different streams, Desalination, 185 (2005) 297306.

[8] S. Deng, Y.P. Ting, Polyethylenimine-Modified Fungal Biomass as a High-Capacity 525 Biosorbent for Cr(VI) Anions: Sorption Capacity and Uptake Mechanisms, Environ. Sci. Technol., 39 (2005) 8490-6.

[9] M.X. Loukidou, K.A. Matis, A.I. Zouboulis, M. Liakopoulou-Kyriakidou, Removal of As(V) from wastewaters by chemically modified fungal biomass, Water Res., 37 (2003) 454452.

530 [10] S. Tangvijitsri, C. Saiwan, C. Soponvuttikul, J.F. Scamehorn, Polyelectrolyte-enhanced ultrafiltration of chromate, sulfate, and nitrate, Sep. Sci. Technol., 37 (2002) 993-1007.

[11] N. Hankins, N. Hilal, O.O. Ogunbiyi, B. Azzopardi, Inverted polarity micellar enhanced ultrafiltration for the treatment of heavy metal polluted wastewater, Desalination, 185 (2005) 185-202.

535 [12] Y. Sato, M. Kang, T. Kamei, Y. Magara, Performance of nanofiltration for arsenic removal, Water Res., 36 (2002) 3371-7.

[13] L. Gzara, M. Dhahbi, Removal of chromate anions by micellar-enhanced ultrafiltration using cationic surfactants, Desalination, 137 (2001) 241-50.

[14] M. Shafiquzzaman, M.S. Azam, J. Nakajima, Q.H. Bari, Investigation of arsenic removal 540 performance by a simple iron removal ceramic filter in rural households of Bangladesh, Desalination, 265 (2011) 60-6.

[15] N. Hilal, G. Busca, N. Hankins, A.W. Mohammad, The use of ultrafiltration and nanofiltration membranes in the treatment of metal-working fluids, Desalination, 167 (2004) 227-38.

545 [16] L.C. Shen, X.T. Nguyen, N.P. Hankins, Removal of heavy metal ions from dilute aqueous solutions by polymer-surfactant aggregates: A novel effluent treatment process, Sep. Purif. Technol., 152 (2015) 101-7.

[17] L.C. Shen, A. Lo, X.T. Nguyen, N.P. Hankins, Recovery of heavy metal ions and recycle of removal agent in the polymer-surfactant aggregate process, Sep. Purif. Technol., 159 (2016) $550 \quad 169-76$.

[18] J. Penfold, R. Thomas, D. Taylor, Polyelectrolyte/surfactant mixtures at the air-solution interface, Current opinion in colloid \& interface science, 11 (2006) 337-44.

[19] C.G. Bell, C.J.W. Breward, P.D. Howell, J. Penfold, R.K. Thomas, Macroscopic Modeling of the Surface Tension of Polymer-Surfactant Systems, Langmuir, 23 (2007) 6042-52. 
555 [20] G. Nizri, S. Lagerge, A. Kamyshny, D.T. Major, S. Magdassi, Polymer-surfactant interactions: Binding mechanism of sodium dodecyl sulfate to poly(diallyldimethylammonium chloride), J. Colloid Interface Sci., 320 (2008) 74-81.

[21] M.A. Winnik, S.M. Bystryak, C. Chassenieux, V. Strashko, P.M. Macdonald, J. Siddiqui, Study of Interaction of Poly(ethylene imine) with Sodium Dodecyl Sulfate in Aqueous Solution 560 by Light Scattering, Conductometry, NMR, and Microcalorimetry, Langmuir, 16 (2000) 4495510.

[22] E. Fuguet, C. Ràfols, M. Rosés, E. Bosch, Critical micelle concentration of surfactants in aqueous buffered and unbuffered systems, Anal. Chim. Acta, 548 (2005) 95-100.

[23] J. Zhang, R.K. Thomas, J. Penfold, Interaction of oppositely charged polyelectrolyte-ionic 565 surfactant mixtures: adsorption of sodium poly(acrylic acid)-dodecyl trimethyl ammonium bromide mixtures at the air-water interface, Soft Matter, 1 (2005) 310-8.

[24] D.J.F. Taylor, R.K. Thomas, P.X. Li, J. Penfold, Adsorption of Oppositely Charged Polyelectrolyte/Surfactant Mixtures. Neutron Reflection from Alkyl Trimethylammonium Bromides and Sodium Poly(styrenesulfonate) at the Air/Water Interface: The Effect of 570 Surfactant Chain Length, Langmuir, 19 (2003) 3712-9.

[25] D.J.F. Taylor, R.K. Thomas, J. Penfold, The Adsorption of Oppositely Charged Polyelectrolyte/Surfactant Mixtures: Neutron Reflection from Dodecyl Trimethylammonium Bromide and Sodium Poly(styrene sulfonate) at the Air/Water Interface, Langmuir, 18 (2002) 4748-57.

575 [26] E. Fegyver, R. Mészáros, Complexation between Sodium Poly (styrenesulfonate) and Alkyltrimethylammonium Bromides in the Presence of Dodecyl Maltoside, The Journal of Physical Chemistry B, 119 (2015) 5336-46.

[27] P. Carpena, J. Aguiar, P. Bernaola-Galván, C. Carnero Ruiz, Problems associated with the treatment of conductivity-concentration data in surfactant solutions: simulations and experiments, Langmuir, 18 (2002) 6054-8. 